\title{
A Role for Sigma Receptors in Stimulant Self Administration and Addiction
}

\author{
Jonathan L. Katz *, Tsung-Ping Su, Takato Hiranita, Teruo Hayashi, Gianluigi Tanda, Theresa \\ Kopajtic and Shang-Yi Tsai
}

Psychobiology and Cellular Pathobiology Sections, Intramural Research Program, National Institute on Drug Abuse, National Institutes of Health, Department of Health and Human Services, Baltimore, MD, 21224, USA

* Author to whom correspondence should be addressed; E-Mail: Jkatz@intra.nida.nih.gov.

Received: 16 May 2011; in revised form: 11 June 2011 / Accepted: 13 June 2011 /

Published: 17 June 2011

\begin{abstract}
Sigma $_{1}$ receptors $\left(\sigma_{1} \mathrm{Rs}\right)$ represent a structurally unique class of intracellular proteins that function as chaperones. $\sigma_{1}$ Rs translocate from the mitochondria-associated membrane to the cell nucleus or cell membrane, and through protein-protein interactions influence several targets, including ion channels, G-protein-coupled receptors, lipids, and other signaling proteins. Several studies have demonstrated that $\sigma \mathrm{R}$ antagonists block stimulant-induced behavioral effects, including ambulatory activity, sensitization, and acute toxicities. Curiously, the effects of stimulants have been blocked by $\sigma \mathrm{R}$ antagonists tested under place-conditioning but not self-administration procedures, indicating fundamental differences in the mechanisms underlying these two effects. The self administration of $\sigma \mathrm{R}$ agonists has been found in subjects previously trained to self administer cocaine. The reinforcing effects of the $\sigma \mathrm{R}$ agonists were blocked by $\sigma \mathrm{R}$ antagonists. Additionally, $\sigma \mathrm{R}$ agonists were found to increase dopamine concentrations in the nucleus accumbens shell, a brain region considered important for the reinforcing effects of abused drugs. Although the effects of the $\sigma \mathrm{R}$ agonist, DTG, on dopamine were obtained at doses that approximated those that maintained self administration behavior those of another agonist, PRE-084 required higher doses. The effects of DTG were antagonized by non-selective or a preferential $\sigma_{2} \mathrm{R}$ antagonist but not by a preferential $\sigma_{1} \mathrm{R}$ antagonist. The effects of PRE-084 on dopamine were insensitive to $\sigma \mathrm{R}$ antagonists. The data suggest that the self administration of $\sigma \mathrm{R}$ agonists is independent of dopamine and the findings are discussed in light of a hypothesis that cocaine has both intracellular actions mediated by $\sigma \mathrm{Rs}$, as well as extracellular actions mediated through conventionally studied mechanisms.
\end{abstract}


The co-activation and potential interactions among these mechanisms, in particular those involving the intracellular chaperone $\sigma \mathrm{Rs}$, may lead to the pernicious addictive effects of stimulant drugs.

Keywords: sigma receptors; drug abuse; cocaine; self-administration; reinforcing effects

\section{Introduction}

We recently reported on the reinforcing effects of sigma receptor $(\sigma \mathrm{R})$ agonists in rats that had a history of cocaine self administration. That rats would self administer a $\sigma \mathrm{R}$ agonist was a surprising outcome. Several previous studies had demonstrated that $\sigma \mathrm{R}$ agonists were ineffective in behavioral procedures that were indicative of reinforcing effects (see below). Thus, the present paper explores the finding of reinforcing effects of $\sigma \mathrm{R}$ agonists further with regard to its implications for the role of $\sigma \mathrm{Rs}$ in the abuse of cocaine, drug abuse in general, adaptations to cocaine exposure, and the potential treatment of stimulant abuse.

There have been a number of comprehensive reviews that have focused on the potential of $\sigma \mathrm{R}$ antagonists as treatments for stimulant abuse (e.g. [1-3]), There also are a number of reviews of the behavioral effects of various ligands for the $\sigma \mathrm{R}$ ([e.g. [4,5]). The interested reader is referred to those papers for a more comprehensive overview and an introduction to the literature on the behavioral pharmacology of $\sigma$ Rs.

The present paper will provide a brief overview of the history of research on $\sigma$ Rs and the current understanding of the cell biology of $\sigma$ Rs. We will then review the literature on $\sigma \mathrm{R}$ agonists with a focus on effects indicative of abuse liability - e.g. effects on dopamine (DA) in brain regions critical for reinforcing effects, locomotor stimulation, subjective discriminative-stimulus effects, self administration, and place conditioning - in light of the finding that $\sigma \mathrm{R}$ agonists can be self administered. Finally, we will further examine several results with cocaine focusing on $\sigma$ Rs that may have implications for the reinforcing effects of $\sigma \mathrm{R}$ ligands.

As the history of $\sigma \mathrm{R}$ research clearly indicates, there have been a number of false starts, quirks, and obstacles due to the need for refinement of techniques and a better understanding of the ligands used to assess actions at $\sigma$ Rs. Consequently, the present review will focus on ligands that are currently understood to be relatively selective for $\sigma$ Rs and will only when necessary include studies conducted with drugs that were previously thought to be $\sigma \mathrm{R}$ ligands but have been proven less selective.

\subsection{History of $\sigma R s$}

The initial proposal by Martin and colleagues [6] was that $\sigma$ Rs were a subtype of opioid receptor that were responsible for "psychotomimetic" effects of various opioid agonists, including the prototype agonist, SKF 10,047. However, subsequent studies indicated that these effects of SKF 10,047 were insensitive to blockade by opioid-receptor antagonists such as naloxone [7]. Due to cross-recognition of various putative $\sigma \mathrm{R}$ ligands such as SKF 10,047 at $\sigma \mathrm{Rs}$ and the high-affinity PCP binding site located within the NMDA glutamate receptor complex [8], and similar behavioral effects of these 
drugs [9], confusion reigned. The subsequent identification and characterization of more selective ligands, including dizocilpine for the PCP site [10] and DTG for sigma sites [11] allowed for the pharmacological identification of $\sigma \mathrm{R}$ sites that were unique from other known binding sites in the central nervous system (see [12] for a review). Pharmacological and molecular studies have distinguished two subtypes of $\sigma$ Rs. The $\sigma_{1} \mathrm{R}$ has been cloned and characterized as a $24 \mathrm{kDa}$ single polypeptide having no homology with any other known mammalian proteins. In contrast, the $\sigma_{2} \mathrm{R}$ is a 18-21 kDa protein that has not yet been cloned. Consequently, much more is known about the $\sigma_{1} \mathrm{R}$ than the $\sigma_{2} R$. Subsequent studies have indicated that $\sigma$ Rs are expressed throughout the CNS and have been implicated in a variety of physiological functions and disease states [13].

\subsection{Current Understanding of $\sigma R$}

\subsubsection{Cell Biology}

Structure and molecular function of the $\sigma_{l} R$. The $\sigma_{1} \mathrm{R}$ is an integral membrane protein predominantly expressed at the endoplasmic reticulum (ER). The $\sigma_{1} R$ possesses two membrane-spanning domains at the $\mathrm{N}$-terminus and the center of the protein [14]. The second transmembrane domain and the putative membrane-anchoring domain at the $\mathrm{C}$-terminus are postulated to comprise a ligand-binding pharmacophore $[15,16]$. The $\sigma_{1} \mathrm{R}$ shares no homology with any mammalian proteins, but shares $30 \%$ identity with a yeast $\mathrm{C} 8 \mathrm{-C} 7$ sterol isomerase [17]. Interestingly, the second transmembrane domain of the $\sigma_{1} \mathrm{R}$ shares over $80 \%$ identity with the sterol-binding pocket of sterol isomerase [17], supporting a notion that the $\sigma_{1} R$ is a sterol-binding protein utilizing the membrane-embedded domain for the association with lipid ligands.

The C-terminus of the $\sigma_{1} \mathrm{R}$ possesses chaperone activity that prevents protein aggregation [14]. It has been suggested that the chaperone domain resides in the lumen of the ER [14], thus $\sigma_{1}$ Rs stabilize ER lumenal and/or ER membrane proteins. The chaperone activity of the $\sigma_{1} \mathrm{R}$ is regulated by a direct protein-protein interaction with another ER chaperone, binding immunoglobulin protein/78 $\mathrm{kDa}$ glucose-regulated protein (BiP/GRP-78) [14] (Figure 1). The striking characteristic of the $\sigma_{1} \mathrm{R}$ is that the chaperone activity can be manipulated by synthetic or endogenous ligands or by cations such as $\mathrm{Ca} 2+$ in a clear agonist-antagonist manner [14,18] (Figure 1). The $\sigma_{1} \mathrm{R}$ in complex with BiP is basically in the dormant state [14]. Upon binding of $\sigma_{1} \mathrm{R}$ agonists or the depletion of $\mathrm{Ca} 2+$ in the ER, $\sigma_{1} R s$ dissociate from BiP, thereby shifting to the active state $[14,18]$. In contrast, $\sigma_{1} R$ antagonists strengthen the association with BiP, thus inhibiting the action of agonists [14,18]. Accordingly, in living systems the chaperone activity is rapidly activated either by applications of $\sigma_{1} \mathrm{R}$ agonists or by activation of IP3 receptors via Gq-coupled metabotrophic receptors at the plasma membrane [14]. Further, a recent study demonstrated that oxidative stress also regulates the association between BiP and $\sigma_{1} \mathrm{R}$ [19]. Thus, a wide range of neuronal activities, which lead to oxidative stress or Ca2+ mobilization, including dopaminergic neural transmission, might contribute to the dissociation of the $\sigma_{1} \mathrm{R}$ from BiP, though this possibility has not been tested in vivo.

Subcellular distribution of $\sigma_{1} R s$. Since the early proposal of the sigma "opioid" receptor [20], a large amount of research was directed at assessing actions of $\sigma_{1}$ Rs at the plasma membrane, particularly actions related to trimeric G proteins [21]. Nevertheless, no conclusive evidence had been 
provided to support the direct coupling of $\sigma_{1}$ Rs to plasma membrane $G$ proteins. Following the successful cloning of $\sigma_{1} \operatorname{Rs}$ [17], molecular biological or immunological approaches have been aggressively introduced in the research field to explore the molecular function and precise subcellular localization of $\sigma_{1}$ Rs. In terms of subcellular localization of $\sigma_{1}$ Rs, results from a line of recent studies are briefly summarized as follows: 1) The majority of $\sigma_{1}$ Rs localizes at the ER (including nuclear envelopes) in a variety of cells or organs; 2) $\sigma_{1}$ Rs tend to form clusters at ER membranes; 3) Unambiguous evidence supporting a significant level of $\sigma_{1} R$ accumulation at plasma membranes has not been convincingly provided; 4) The ER distribution and the level of $\sigma 1$ Rs can be dynamically or rapidly changed under certain conditions.

Figure 1. Potential synaptic actions of $\sigma 1$ Rs.

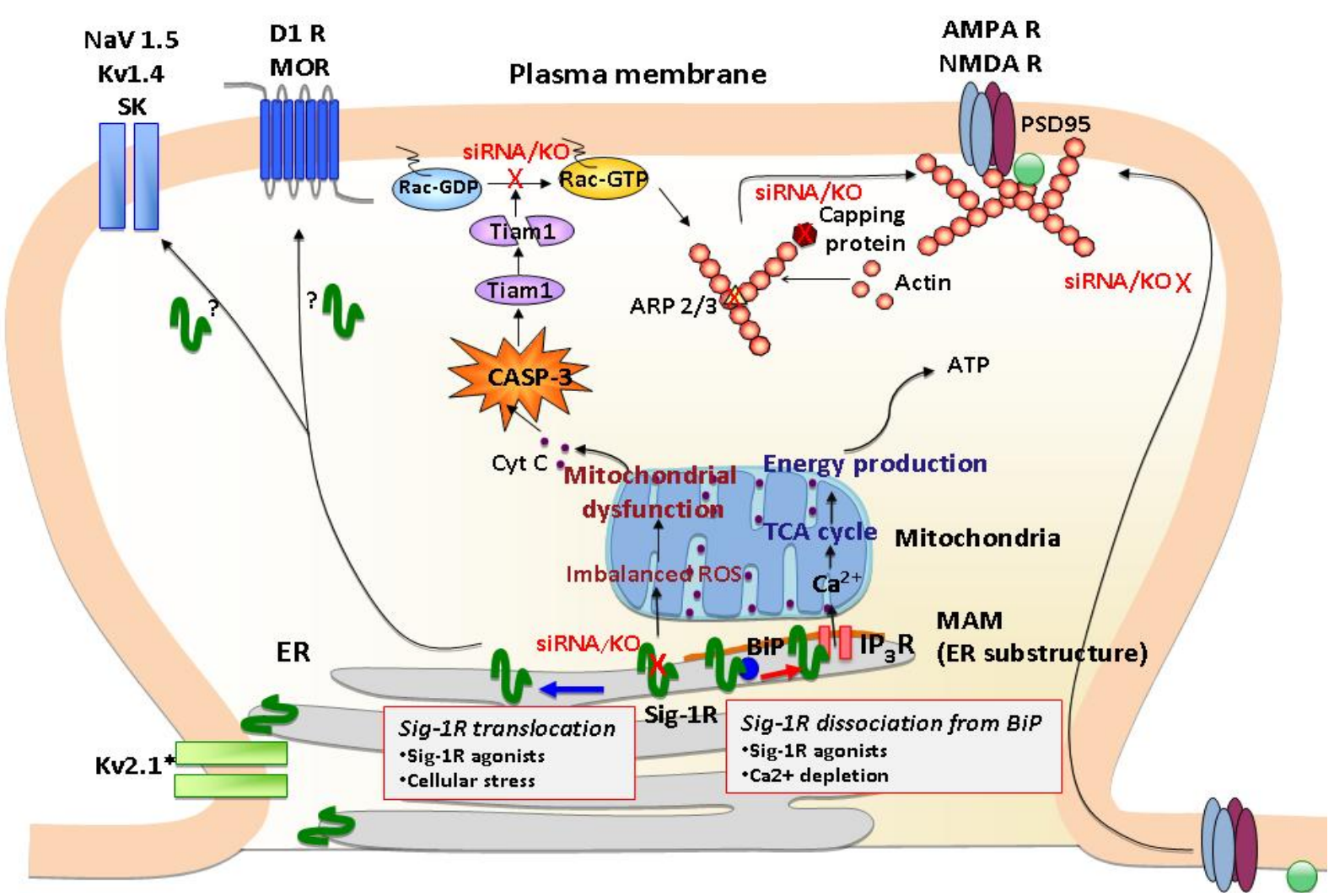

$\sigma_{1}$ Rs are ER proteins highly clustered at the mitochondria-associated ER membrane (MAM). Under un-stressed conditions, $\sigma_{1}$ Rs regulate IP3 receptor-mediated Ca2+ mobilization at the MAM. Ca2+ directly influxed from MAM to mitochondria activates ATP production. When $\sigma_{1}$ Rs at the MAM are depleted in neurons, it causes various mitochondrial dysfunctions, including aggregated mitochondria, membrane potential changes and increased ROS production. These are followed by cytochrome c release and the activation of caspase-3. The activated caspase-3 induces the cleavage and inactivation of the Rac 1 specific GEF Tiam1, leading to the failure of Rac GDP switching to Rac GTP. The failure of the Tiam1-Rac pathway causes the disrupted cytoskeleton network and actin polymerization, that partly involves reduced activities of capping proteins and branching proteins Arp2/3. Consequently, neurons depleted with $\sigma_{1}$ Rs fail to promote maturation of dendritic spines and recruitment of AMPA/NMDA to post-synaptic membranes as evident of those receptors remained in the dendritic shaft. $\sigma_{1}$ Rs may also modulate post-synaptic proteins including a variety of ion channels (Na2+, $\mathrm{K}+$ channels) and $\mathrm{G}$ protein-coupled receptors (DA D2, $\mu$ opioid receptors) by translocating to the proximity of postsynaptic density. 
One of the major loci where $\sigma_{1}$ Rs cluster is the ER subdomain physically associating with mitochondria (mitochondria-associated ER membrane: MAM) [14] (Figure 1). The MAM is a center place where the ER directly provides $\mathrm{Ca} 2+$ to mitochondria via IP3 receptors and transports phospholipids and sterols to mitochondria [22]. The Ca2+ provided from MAM to mitochondria is known to activate the tricarboxylic acid (TCA) cycle and ATP synthesis [23]. $\sigma_{1} \mathrm{R}$ chaperoning IP3 receptors at the MAM potentiates $\mathrm{Ca} 2+$ influx from the MAM to mitochondria [14], thus likely regulating mitochondrial bioenergetics and reactive oxygen species (ROS) generation (Figure 1).

A recent study demonstrated that $\sigma_{1}$ Rs are also highly clustered at the thin layers of ER cisternae adjacent to the post-synaptic plasma membranes of the ventral horn spinal motor neurons [24]. The post-synaptic clusters of $\sigma_{1}$ Rs are specific to cholinergic synapses [24]. Thus, in specific neuron types, $\sigma_{1}$ Rs are constitutively expressed at the ER subdomains apposing the plasma membrane (Figure 1). Similar plasma membrane clustering of $\sigma_{1}$ Rs was also observed in living NG108 neuroblastoma $\mathrm{x}$ glioma hybrid cells when enhanced yellow fluorescent protein-tagged $\sigma_{1}$ Rs were expressed [14].

Mobility and translocation of $\sigma_{1} R s$. The demand for elucidating the molecular mechanism by which $\sigma_{1}$ Rs regulate plasma membrane events is expanding as various novel roles are unveiled for $\sigma_{1}$ Rs in the regulation of $\mathrm{G}$ protein-coupled receptors (GPCRs) and ion channels [25-28]. $\sigma_{1}$ Rs tonically regulate activity of potassium, NMDA, and sodium channels [25,26,29] (Figure 1). Recent studies indicate possible interactions between $\sigma_{1}$ Rs and GPCRs, such as $\mu$ opioid and DA D1 receptors [27,28] (Figure 1). In light of the nature of molecular chaperones, studies suggest that $\sigma_{1}$ Rs regulate plasma membrane proteins via physical protein-protein interactions [25,27,28]. Although further studies are essential for clarification, growing evidence from recent molecular and cell biological studies is beginning to elucidate possible mechanisms that may in part explain plasma membrane actions of $\sigma_{1}$ Rs. Three potential mechanisms are proposed in following.

Cellular stress or $\sigma_{1} \mathrm{R}$ agonists are shown to mobilize $\sigma_{1}$ Rs at the ER membrane [30,31] (Figure 1). The highly mobile $\sigma_{1}$ Rs move along the ER membranes from deep intracellular loci (e.g., MAM) to more peripheral subcellular locations [31]. At the MAM $\sigma_{1}$ Rs are highly stationary [31], possibly due to their tight association with cholesterol/ceramide-rich lipid microdomains therein [32]. However, over $70 \%$ of $\sigma_{1}$ Rs localized at non-MAM ER membranes (e.g., ER membranes in neurites) are highly mobile with a mobility speed that reaches around $8-10 \mu \mathrm{m} / \mathrm{min}[31,33]$. Upon ligand binding, $\sigma_{1} \mathrm{Rs}$ redistribute from detergent-insoluble lipid microdomains to soluble membrane domains [34,35]. $\sigma_{1} R$ agonists may unleash $\sigma_{1} \mathrm{R}$ proteins from lipid microdomains, thus gaining mobility at the ER. The resulting peripherally distributed $\sigma_{1} R s$, as seen at cholinergic synapses of motor neurons [24], may be able to reach close proximity with the plasma membrane. Therefore, translocation may enable $\sigma_{1}$ Rs from the ER to physically associate with proteins at the plasma membrane (Figure 1).

Some ER chaperones are known to translocate from ER to other intracellular organelles, or be released to the outside of cells [36,37]. The mechanism underlying the translocation of ER chaperones involves the hindrance of ER retention/retrieval motif via protein-protein interactions [37,38]. The ER localization of $\sigma_{1}$ Rs seems to be determined by the double-arginine ER retention motif at the $\mathrm{N}$-terminus that is utilized for a retrieval of ER proteins from coat protein complex-I (COP-I)-operated ER-Golgi secretory pathway to the ER. The deletion of the motif causes the exclusive relocation of $\sigma_{1}$ Rs from ER to the cytoplasm or cytosolic lipid droplet-like structures [34]. The wild-type $\sigma_{1}$ Rs are indeed co-immunoprecipitated with COP-I, indicating that $\sigma_{1} \mathrm{Rs}$ are actively retrieved from the 
ER-Golgi secretory pathway to the ER. In contrast, mutations at the double-arginine motif disrupt the association of $\sigma_{1}$ Rs with COP-I [39]. A recent bioinformatics study identified that 84 mammalian membrane proteins possess the double-arginine motif in the first 25 amino acids [39]. Interestingly, only 24 of these proteins localize at the ER or sarcoplasmic reticulum [39]. Several proteins with the double arginine motif successfully escape from the ER retrieval machinery and reach plasma membranes that include the plasma membrane ATP-sensitive potassium channel (Kir6.1/2), and $\mathrm{GABA}_{B}$ receptor $\mathrm{GB}_{1}$ subunit [39]. The NMDA receptor NR1-1a subunit is also known to possess the triple-arginine ER retention motif [40]. Whether the interaction of $\sigma_{1}$ Rs with ion channel subunits or GPCRs at the ER may hinder the double-arginine motif of $\sigma_{1}$ Rs, thus triggering the departure of the complex for the plasma membrane is an untested, but intriguing possibility.

$\sigma_{1}$ Rs may also modulate plasma membrane proteins by controlling their folding and secretion at the ER level. Virtually all plasma membrane proteins are synthesized at the ER. Newly synthesized proteins are properly folded with the aid of ER molecular chaperones followed by entering the ER-Golgi secretory pathway for further modifications and the delivery to the final destination (e.g., plasma membrane) [41]. A recent study demonstrated that a $\sigma_{1} R$ agonist indeed potentiates the secretion of brain-derived neurotrophic factor (BDNF) from neuroblastoma cells [42]. The protein transport via the ER-Golgi secretory pathway is also controlled by lipids comprising the transport vesicles [43]. Cholesterol and sphingolipids which form lipid raft microdomains play a pivotal role in trafficking and sorting of plasma membrane proteins at the ER and Golgi [43]. Importantly, recent studies indicate that $\sigma_{1}$ Rs regulate lipid transport at the ER, and lipid raft formation at the plasma membrane $[34,44,45]$. These findings support a notion that $\sigma_{1}$ Rs may be involved in the transport of proteins as well as lipids between ER and plasma membranes. It should be mentioned that the transport of proteins from the ER to the plasma membrane is highly efficient, generally taking only a few to $30 \mathrm{~min}$ [41]. Specifically, protein delivery at dendritic spines is thought to be much faster because all machineries necessary for protein synthesis and trafficking are packed in the small structure $[46,47]$. From this viewpoint, it is plausible to speculate that $\sigma_{1} R s$ may indirectly regulate the protein expression on the surface of neurons in a relatively short time frame by controlling protein transport.

$\sigma_{1} R s$ and cellular morphologies. $\sigma_{1}$ Rs may affect a wide range of cellular functions by regulating cell morphologies. Earlier studies found that $\sigma_{1}$ Rs promote neurite sprouting in PC12 cells. Selective $\sigma_{1} \mathrm{R}$ agonists, though having no effect of their own, were able to enhance nerve growth factor (NGF)-induced neurite sprouting. Additionally, NGF as well as chronic treatment with $\sigma_{1} \mathrm{R}$ agonists were shown to up-regulate endogenous $\sigma_{1} \mathrm{R}$ expression in PC12 cells; the process is essential for promoting neurite sprouting by $\sigma_{1} \mathrm{R}$ ligands [48]. A later, similar finding of NGF-induced neurite outgrowth in PC12 cells revealed that the $\sigma_{1} \mathrm{R}$ agonist SA4503 stimulates $\sigma_{1} \mathrm{R}$ binding to IP3 receptors as well as the pathways downstream from trophic factor receptors that include PLC- $\gamma$, PI3K, p38 mitogen-activated protein kinase (MAPK), JNK and Pas/Raf/MAPK [49].

Recently, the impact of $\sigma_{1}$ Rs on synaptic plasticity and the consequential effects on neuronal function have begun to be elucidated. In $\sigma_{1} \mathrm{R}$ deficient hippocampal neurons, aberrant morphologies have been observed [50]. $\sigma_{1}$ Rs are critical regulators for dendrite extension and branching during early stages of neuronal development. At later developmental stages when neurons are approaching maturation, $\sigma_{1} R s$ facilitate the formation and maintenance of dendritic spines and functional synapses [50]. Thus, $\sigma_{1} R s$ regulate both the early (e.g., neurite sprouting, dendrite extension, and dendrite branching) and late 
(e.g., spine maturation, synaptogenesis) stages of neuronal differentiation. When $\sigma_{1}$ Rs were depleted at the late stage of neuronal differentiation by siRNAs, neurons failed to form the mushroom-like spines as well as functional synapses that possess clustered assemblies of AMPA/NMDA receptors and postsynaptic density scaffolding protein PSD-95 [50] (Figure 1). The aberrant morphologies caused by $\sigma_{1} \mathrm{R}$ depletion were associated with malfunctions of mitochondria followed by accumulation of ROS and activation of caspase-3 (CASP-3). In $\sigma_{1}$ R knockdown neurons, ROS-activated CASP-3 degrades T-lymphoma invasion and metastasis-inducing protein 1 (Tiam1) by proteolytic cleavages, thus subsequently reducing the active form of Rac1-GTP [50] (Figure 1). Both the mitochondria dysfunction and aberrant neuronal morphogenesis caused by $\sigma_{1} \mathrm{R}$ knockdown were blocked by ROS scavengers, such as Tempol and $\mathrm{N}$-acetylcysteine [50], indicating that $\sigma_{1}$ Rs are key modulators in maintaining the balance of oxidative stress in the neurons. A recent microarray analysis of rat primary neurons further demonstrated that the $\sigma_{1} \mathrm{R}$ knockdown causes alterations of a cluster of transcripts involved in remodeling of the actin-based cytoskeleton network. The transcripts include those of actin capping proteins and actin-related protein 2/3 (ARP2/3) [51] (Figure 1). Together, these findings indicate that $\sigma_{1}$ Rs are important regulators in cellular morphology and neuronal plasticity.

\subsubsection{Receptor Binding}

A wide variety of compound structures bind to the $\sigma \mathrm{R}$, which has made the study of structure-activity relationships difficult [52]. Obstacles to progress included difficulties in settling on the most selective radioligands for studies that were capable of differentiating the $\sigma \mathrm{R}$ from PCP binding sites. The discovery of DTG as a selective $\sigma \mathrm{R}$ ligand was a substantial advance in that regard [11]. In addition, the initial lack of appreciation that there are two types of $\sigma$ Rs also impeded progress. The characterization of $(+)$-pentazocine as a prototype selective $\sigma_{1} \mathrm{R}$ agonist was an equally important advance $[53,54]$. However, there are no ligands that can serve equally well as prototype selective $\sigma_{2} R$ agonists. Most commonly, DTG is used as a radioligand to label $\sigma_{2}$ Rs with adequate concentrations of unlabeled $(+)$-pentazocine to block the labeling of $\sigma_{1}$ Rs. Using these techniques more than adequate progress can be made in characterizing the binding of various ligands [55].

In a recent study primarily focused on the effects of $\sigma \mathrm{R}$ agonists on DA neurotransmission, Garcés-Ramírez et al. [56] further characterized the binding of several prototype ligands at $\sigma_{1}$ and $\sigma_{2}$ binding sites using $\left[{ }^{3} \mathrm{H}\right](+)$-pentazocine to label $\sigma_{1}$ Rs and $\left[{ }^{3} \mathrm{H}\right] \mathrm{DTG}$ with cold $(+)$-pentazocine to label $\sigma_{2}$ Rs. The binding of the radioligands was consistent with previous descriptions. In addition, PRE-084, a ligand that selectively binds $\sigma$ Rs over PCP binding sites [57], was reported to have affinity at $\sigma_{1}$ Rs approximately 600 -fold greater than that for $\sigma_{2}$ Rs. Thus, PRE-084 can be used in vitro and in vivo as a selective $\sigma_{1} \mathrm{R}$ agonist.

A number of studies have suggested a multiplicity of binding sites beyond the sites commonly accepted as $\sigma_{1}$ and $\sigma_{2}$ Rs [e.g. 58-60]. In the study by Garcés-Ramírez et al. [56], the binding data for $\left[{ }^{3} \mathrm{H}\right] \mathrm{DTG}$ were better fit to a two-site than a single-site model. Figure 2 shows the results of a homologous competition study with DTG showing inflections in the displacement curve indicative of two binding sites with $\mathrm{K}_{d}$ values of 21.9 and 3,520 nM. The $\mathrm{K}_{\mathrm{d}}$ value for the higher affinity site is comparable to that reported previously for DTG at $\sigma_{2} \mathrm{Rs}$. Additionally, the $\mathrm{K}_{\mathrm{i}}$ values obtained with several compounds [56] further suggest that the DTG high-affinity site is the site recognized as the $\sigma_{2} R$. 
In contrast, the low-affinity binding of DTG and the $\mathrm{K}_{\mathrm{i}}$ values obtained for the other compounds studied were substantially below the values considered to be their $\sigma_{2} \mathrm{R}$ affinities. As this binding was assessed in the presence of high concentrations of $(+)$-pentazocine $(200 \mathrm{nM})$, the additional site appears to be a unique site different from the previously characterized $\sigma_{1}$ and $\sigma_{2} \mathrm{R}$ sites. Whether and how this low-affinity DTG binding site is related to previously identified multiple $\sigma \mathrm{R}$ binding sites has not yet been determined.

Figure 2. Homologous competition of radiotracer and nonradioactive DTG at guinea pig membranes.

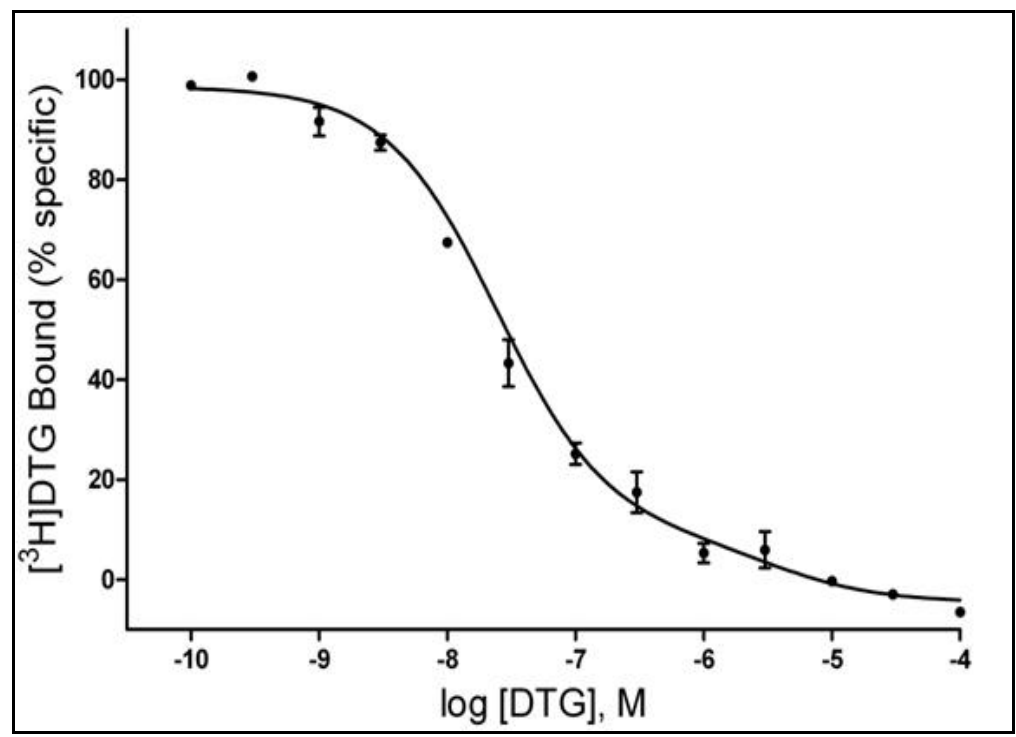

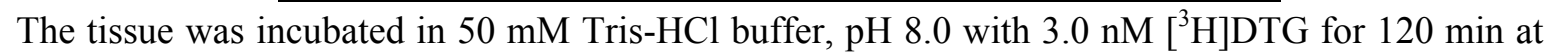
room temperature. Each tube contained $3 \mathrm{nM}\left[{ }^{3} \mathrm{H}\right] \mathrm{DTG}$ (specific activity $48 \mathrm{Ci} / \mathrm{mmol}$ ), $200 \mathrm{nM}$ $(+)$-pentazocine, and $8.0 \mathrm{mg}$ tissue. Non-specific binding was defined by addition of $10 \mu \mathrm{M}$ haloperidol. Reaction was terminated by filtration through Whatman GFB filters presoaked in $0.05 \%$ polyethylenimine. The curve is representative of three independent experiments carried out in triplicate.

\subsection{3. $\sigma \mathrm{R}$ Agonists and Antagonists}

What constitutes agonist and antagonist actions at $\sigma \mathrm{Rs}$, and which ligands function in each of the two manners, have been significant problems throughout the history of research on $\sigma$ Rs. The review by Walker et al. [52] describes much of the early research attempting to characterize various ligands with regard to their agonist or antagonist actions. Several factors hindered progress. Foremost is that the research approached these questions pertaining to the functionality of ligands at the binding site using a model based on GPCRs. As the sections above attest, the GPCR model is far enough from our current understanding of $\sigma$ Rs to direct the research into less than profitable avenues. As described above, the chaperone activity of the $\sigma_{1} \mathrm{R}$ can respond in clear agonist or antagonist modes, which can be assessed by its association with BiP. Agonists shift the receptor from the dormant state of BiP association to dissociation and antagonists strengthen the association with $\mathrm{BiP}$, and inhibit the action of agonists $[14,18]$. How these molecular activities translate into in vivo actions remains unclear. Many of the compounds generally considered as $\sigma \mathrm{R}$ antagonists are those that block the acute locomotor stimulant 
or toxic effects of cocaine, whereas agonists can shift the cocaine dose-effect curve leftward [12]. Cocaine binds to $\sigma \mathrm{Rs}$, and itself "appears" to act as a $\sigma \mathrm{R}$ agonist at high enough concentrations. Because of cocaine's pre-potent effects on DA systems, this method of identification remains somewhat less than satisfactory, but nonetheless successful.

\subsection{Effects on Neurotransmitters}

In regards to modulation of neurotransmitter release and possibly uptake, $\sigma$ Rs have been shown to interact with GLU, ACh, DA, serotonin (5-hydroxytryptamine, 5-HT), norepinephrine (noradrenaline, $\mathrm{NE}$ ), and $\gamma$-aminobutyric acid (GABA) systems. Some of these neuromodulatory actions could be of interest when related to reinforcing or dependence-producing actions of drugs, and will be described below.

\subsubsection{DA Neurotransmission}

Several fundamental physiological functions have been related to DA neurotransmission, which notoriously underlies drug addiction as well as many different pathological conditions. Brain areas related to DA transmission express $\sigma$ Rs [61], and some of the earliest functional studies indicated a modulation of dopaminergic effects by $\sigma \mathrm{R}$ ligands [e.g. 62]. Thus, it has been with considerable interest that researchers have explored how activation or blockade of $\sigma$ Rs modifies dopaminergic neurotransmission. Moreover, the discovery that stimulant drugs such as cocaine and methamphetamine bind to $\sigma$ Rs has increased attention to $\sigma$ Rs in studies of drug abuse.

As mentioned above, early difficulties in precisely delineating selective ligands for $\sigma$ Rs have to be considered when examining contrasting results described in the literature. For example, (+)-3-PPP, a drug with high affinity for $\sigma$ Rs, has been shown to significantly decrease extracellular DA levels in dialysates from the nucleus accumbens (NAC) [63] or from the striatum [64,65] after systemic administration. BMY-14802, a $\sigma \mathrm{R}$ antagonist with 5- $\mathrm{HT}_{1 \mathrm{~A}}$ agonist effects, attenuated the effect of (+)-3-PPP in the striatum. However, these effects of (+)-3-PPP are more likely the result of its agonist effects on DA D2-like receptors, which produce negative feedback on DA neurons, reducing firing and the release of DA [63].

A decrease in DA levels has also been shown with local administration of high doses of haloperidol, a $\sigma \mathrm{R}$ antagonist, and the agonist, DTG [66,67]. A biphasic effect, an increase followed by a decrease in DA levels, has also been observed after intrastriatal administration of several $\sigma \mathrm{R}$ ligands such as $(+)$-pentazocine, DTG, and (+)-MR200, a non-selective $\sigma \mathrm{R}$ antagonist [66,67]. Moreover, systemic administration of DUP 734, (+)-SKF 10,047, and intrastriatal haloperidol, at low doses, increased DA levels [65,67], while DTG was without effects [65]. Increased DA turnover in the rat frontal cortex was also obtained after acute administration of SA4503, an effect that was blocked by the $\sigma \mathrm{R}$ antagonist, NE-100 [68]. In addition, the effects of repeated administrations of SA4503, once a day for 21 days, was assessed in electrophysiological studies, in which it significantly increased the number of spontaneously active VTA dopaminergic neurons. Those electrophysiological effects were blocked by NE-100 as well [69].

In studies prompted by the finding of reinforcing effects of $\sigma \mathrm{R}$ agonists [70], intravenously administered PRE-084 and DTG dose-dependently and significantly increased DA levels in the rat 
NAC shell [56], a brain area related to the reinforcing effects of drugs [71-73]. The effects of DTG were obtained at doses that approximated those that maintained self-administration behavior [70]. In addition, the effects of DTG were antagonized by BD 1008 (a non-selective $\sigma \mathrm{R}$ antagonist) and SN 79 (a preferential $\sigma_{2} \mathrm{R}$ antagonist) but not by BD 1063 (preferential $\sigma_{1} \mathrm{R}$ antagonist), suggesting that the effect of DTG on DA was mediated by $\sigma_{2}$ Rs but not by $\sigma_{1}$ Rs (Figure 3, top). On the other hand, a significant increase in DA levels produced by PRE-084 was obtained at doses about 30 times higher than those that maintained self-administration behavior. Additionally, the effects of PRE-084 on DA were not significantly attenuated by pretreatments with $\sigma \mathrm{R}$ antagonists (Figure 3, middle), suggesting the effects of PRE-084 on DA release were not mediated by $\sigma$ Rs [56]. This dichotomy in the effects of PRE-084, with self-administration behavior mediated by $\sigma$ Rs at doses that do not elicit increase in NAC shell DA levels (as compared to virtually all drugs abused by humans), and higher doses of PRE-084 that stimulate DA levels but are not mediated by $\sigma$ Rs, suggest a DA-independent central pathway for $\sigma \mathrm{R}$-agonists reinforcing effects [56]. In the same report it was also shown that, in agreement with lack of effects in self administration studies [70], the acute cocaine-induced stimulation of DA levels was not affected by pretreatments with $\sigma \mathrm{R}$ antagonists at doses able to produce full $\sigma \mathrm{R}$ antagonist effects (Figure 3, bottom).

\subsubsection{GLU Neurotransmission}

GLU neurotransmission, as with DA, has also been implicated in drug abuse, with its role purported to be in the various stages that lead from drug use to addiction [74]. Specific neuronal circuits in which GLU is the main neurotransmitter have been shown to be involved in neuronal adaptations that are induced by repeated exposures to abused drugs [75,76]. Modulation of GLU neurotransmission can be an important target of $\sigma \mathrm{R}$ agonists. Moreover, GLU neurotransmission plays a role also in the modulation of the functioning of other neurotransmitter systems, thus its modulation by $\sigma \mathrm{R}$ ligands can have a cascading greater influence than merely on GLU systems alone.

Several studies implicate $\sigma$ Rs as influencing GLU neurotransmission in brain areas that play a role in learning and memory. For example, it has been reported that actions of neurosteroids at $\sigma_{1}$ Rs can enhance spontaneous GLU release in the prelimbic cortex and hippocampus [77,78]. In a report of an elegant series of experiments, Schiess and Partridge [79] suggested that another neurosteroid, pregnenolone sulfate, might act presynaptically through a Gi/o-coupled $\sigma_{1}$-like receptor to modulate basal GLU release. Also, modulation of GLU release by dehydroepiandrosterone (DHEA) has been related to improved performance on an inhibitory avoidance task, possibly due to this neurosteroid's effectiveness in physiologically increasing GLU tone [80].

Recent evidence suggests that neurosteroids facilitate long-term potentiation (LTP) in the rat hippocampus, an effect suggested as being mediated by neurosteroid activation of neuronal $\sigma$ Rs $[29,81,82]$. The pharmacological specificity of the effect has been shown by its prevention with co-administration of the selective $\sigma \mathrm{R}$ antagonist, NE-100. As LTP has been implicated in adaptations concomitant with stimulant self administration [83] these findings have clear implications for stimulant dependence. 
Figure 3. Effects of pretreatments with selective $\sigma \mathrm{R}$ antagonists on DTG-, PRE-084-, and cocaine-induced stimulation of DA levels in dialysates from the NAC shell in rats.

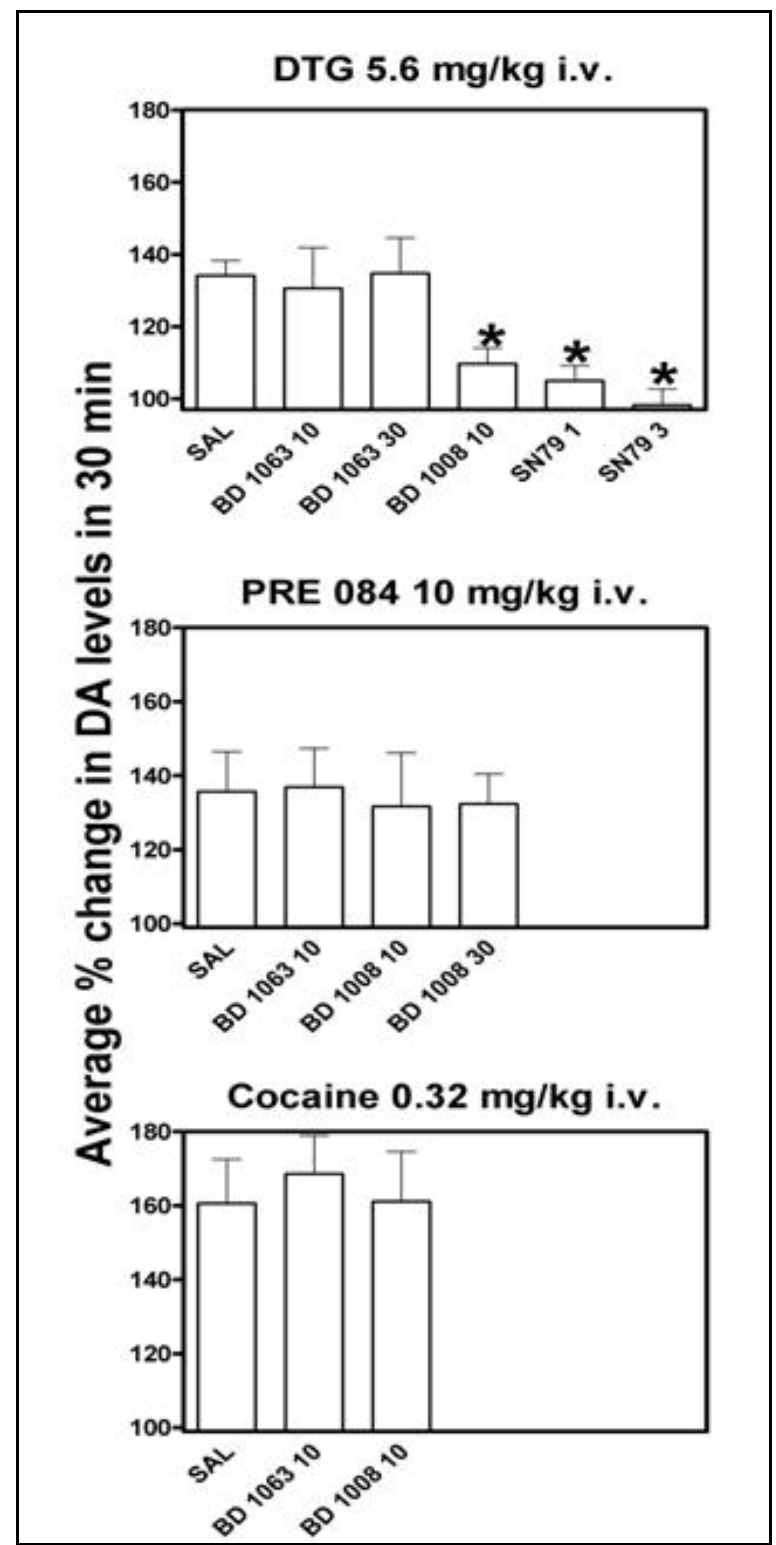

Increased levels of DA were expressed as the average percent change in basal DA values during the first $30 \mathrm{~min}$ after DTG, PRE-084, or cocaine treatment. The top panel shows effects of pretreatments with saline, $1 \mathrm{~mL} / \mathrm{kg}$ i.p.; BD 1063 (a preferential $\sigma_{1} \mathrm{R}$ antagonist), 10 and $30 \mathrm{mg} / \mathrm{kg}$ i.p.; BD 1008 (non-selective $\sigma \mathrm{R}$ antagonist), $10 \mathrm{mg} / \mathrm{kg}$ i.p.; and $\mathrm{SN} 79$ (preferential $\sigma_{2} \mathrm{R}$ antagonist), 1 and $3 \mathrm{mg} / \mathrm{kg}$ i.p., injected 30, 30, 30, 15 and $15 \mathrm{~min}$, respectively, before DTG administration, $5.6 \mathrm{mg} / \mathrm{kg}$ i.v. The middle panel shows effects of pretreatments with saline, $1 \mathrm{~mL} / \mathrm{kg}$ i.p.; BD 1063, $10 \mathrm{mg} / \mathrm{kg}$ i.p.; and BD 1008, 10, and $30 \mathrm{mg} / \mathrm{kg}$ i.p., injected $30 \mathrm{~min}$ before PRE 084 administration, $10.0 \mathrm{mg} / \mathrm{kg}$ i.v. The bottom panel shows effects of pretreatments with saline, $1 \mathrm{~mL} / \mathrm{kg}$ i.p.; BD $1063,10 \mathrm{mg} / \mathrm{kg}$ i.p.; and BD 1008, $10 \mathrm{mg} / \mathrm{kg}$ i.p. injected $30 \mathrm{~min}$ before cocaine administration, $0.32 \mathrm{mg} / \mathrm{kg}$ i.v. The data shown are published results [56], and the reader is referred to that paper for more details and information about the original experiments. concomitant with stimulant self administration [83] these findings have clear implications for stimulant dependence. 
BDNF is a member of a family of growth factors found in brain and periphery that support the modification, growth, and differentiation of neurons and synapses. BDNF has been implicated in various processes related to learning and memory and is active in the hippocampus, cortex, and basal forebrain. It has also been implicated in the development of drug dependence [84-86]. Interactions between GLU release, BDNF, and $\sigma \mathrm{Rs}$ have been shown in studies of the effects of overexpression of $\sigma_{1} \mathrm{Rs}$ on BDNF-induced PLC- $\gamma$ activation and GLU release. In addition, BD 1047 prevents the potentiation of BDNF-induced PLC- $\gamma$ activation and GLU release produced by antidepressant drugs [87].

\subsubsection{ACh Neurotransmission}

$\sigma \mathrm{R}$ agonists and neurosteroids with affinity for $\sigma \mathrm{Rs}$ have been shown to modulate ACh neurotransmission, and the stimulation of ACh release by $\sigma \mathrm{R}$ agonists has been implicated in the improvement of cholinergic-deficit induced memory impairment. Thus $\sigma$ Rs may play a role in modulation of learning and memory processes [88]. As preclinical and clinical studies have suggested the potential of cognitive enhancers in the treatment of stimulant dependence [89] a modulation of ACh systems by $\sigma \mathrm{R}$ ligands may present another avenue for the discovery of treatments for stimulant dependence.

Igmesine potentiated the $\mathrm{KCl}$-evoked release of $\left[{ }^{3} \mathrm{H}\right] \mathrm{ACh}$ from rat hippocampal slices, an effect also produced by $(+)$-SKF 10,047, but not by DTG. Perfusion of the slices with the $\sigma \mathrm{R}$ antagonist, haloperidol, blocked the effects of igmesine and (+)-SKF 10,047 [90]. Using brain microdialysis in rat prefrontal cortex, several $\sigma \mathrm{R}$ agonists including $(+)-3-\mathrm{PPP}, \mathrm{DTG},( \pm)$-pentazocine, and $(+)$-SKF 10,047 dose-dependently increased the extracellular ACh levels. The effect was antagonized by haloperidol [91]. Stereoselectivity and antagonism by haloperidol were also demonstrated in the stimulation of hippocampal extracellular ACh levels and anti-amnesic effects of (+)-SKF 10,047 [92].

The non-selective PCP/ $\mathrm{R}$ ligand, (+)-SKF 10,047, also stimulated ACh overflow in hippocampal slices [93] with a potency greater than that of DTG. In the same study, the striatal extracellular ACh levels were modestly increased by (+)-SKF 10,047, while DTG was without effects. Similar regional specificity for ACh stimulation was found with SA4503, a selective $\sigma_{1} \mathrm{R}$ agonist, with effects in the rat frontal cortex and hippocampus dialysates and without significant effects on striatal ACh release [94,95]. It is also interesting to note that some neuroactive steroids, pregnenolone, DHEA [96], elicit an overlapping pattern of stimulation of ACh release [97], thus acting as $\sigma \mathrm{R}$ agonists.

As mentioned above, cocaine-induced place conditioning has been blocked by $\sigma \mathrm{R}$ antagonists [98,99] but not cocaine self-administration [70,100]. The blocking effects of $\sigma \mathrm{R}$ antagonists on place conditioning procedure could result from the inhibition of ACh neurotransmission (amnesic action) rather than a specific antagonism of the effects of cocaine.

\subsubsection{NE Neurotransmission}

The major abused psychostimulants, cocaine and amphetamines, increase NE neurotransmission after systemic administration [101], an effect which might play a role in the behavioral actions of these drugs [102]. Several $\sigma \mathrm{R}$ ligands have been shown to interact with NE neurotransmission. The effects described below of (+)-3-PPP and haloperidol should be considered with the fact that these drugs also have activity at DA receptors. 
The $\sigma \mathrm{R}$ agonists (+)-pentazocine, BD 737, and DTG, inhibited, while other $\sigma \mathrm{R}$ agonists, igmesine and (+)-3-PPP, facilitated NMDA-evoked overflow of $\left[{ }^{3} \mathrm{H}\right] \mathrm{NE}$ from hippocampal rat slices, without affecting the basal efflux $[103,104]$. Antagonists of $\sigma$ Rs, such as DUP 734, BD 1008, and haloperidol prevented both the facilitation and inhibition of the effects of $\sigma \mathrm{R}$ agonists [103,104]. It was also demonstrated that $\sigma_{2} R s$ might contribute to the regulation of NE release, since a $\sigma_{2} R$ antagonist, BIMU-8, reversed a $\sigma \mathrm{R}$ agonist component of the effect that was not sensitive to $\sigma_{1} \mathrm{R}$ antagonists [105]. Neurosteroids that activate $\sigma$ Rs have been shown to differently modulate the $\mathrm{K}+$-evoked, and NMDA-evoked, release of $\left[{ }^{3} \mathrm{H}\right] \mathrm{NE}$ from hippocampal slices. For example, DHEA sulfate facilitated, while pregnenolone sulfate inhibited NMDA-evoked release of $\left[{ }^{3} \mathrm{H}\right] \mathrm{NE}$, and these effects were prevented by administration of $\sigma \mathrm{R}$ antagonists [106]. Results from the latter study suggest that DHEA sulfate acts as a $\sigma \mathrm{R}$ agonist, and further suggested to the authors that pregnanolone sulfate acts as an inverse agonist. Also, progesterone sulfate mimicked the antagonist effects of haloperidol, suggesting it might also possess antagonist actions at $\sigma$ Rs [106].

\subsubsection{5-HT Neurotransmission}

It is interesting to note that several compounds initially believed to selectively target 5-HT neurotransmission possess affinity for $\sigma \mathrm{Rs}$, and that this feature may play a role in the rapid onset of antidepressant efficacy, as compared to antidepressants that do not show $\sigma \mathrm{R}$ activity [107]. 5-HT systems have also been implicated in various aspects of drug abuse. As with NE systems, many of the most avidly abused stimulant drugs interact with 5-HT neurotransmission, and neurotoxicity caused by several of these drugs impacts 5-HT brain systems [108]. Further $\sigma \mathrm{R}$ ligands can modulate 5-HT neurotransmission, suggesting their involvement in the neurotoxic effects of amphetamines. For example, it has been suggested that DHEA by activating $\sigma_{1}$ Rs can negatively modulate 5 - $\mathrm{HT}_{3}$ receptor activity in pyramidal cells of the pre-limbic cortex. This effect, in turn, has been shown to inhibit 5-HT-evoked GLU-release, which is mediated by activation of 5- $\mathrm{HT}_{3}$ receptors [109]. A pharmacological selective role for $\sigma_{1}$ receptors in this effect has been shown mimicking the effects of DHEA with carbetapentane, a $\sigma_{1}$ agonist, and blocking the effect with AC915, a $\sigma_{1}$ receptor antagonist [109]. Another selective $\sigma \mathrm{R}$ antagonist, MS-377, when injected alone had no significant effects on 5-HT or DA release in the rat striatum or in the medial prefrontal cortex. However, pretreatment with MS-377 significantly attenuated the behavioral effects of PCP, likely through the inhibition of PCP-induced increases in DA and 5-HT release [110].

Several studies demonstrated an effect of $\sigma \mathrm{R}$ agonists on the firing of 5-HT neurons in the dorsal raphe nucleus (DRN). For example, a complex relationship between $\sigma \mathrm{R}$ agonists and 5-HT neurotransmission has been shown by Bermack and Debonnel [111]. Using extracellular in vivo recordings in anaesthetized rats (+)-pentazocine and 4-IBP, but not PRE-084 or igmesine, markedly increased 5-HT firing after 2 or 21 days of treatment. In addition, the selective $\sigma_{1} \mathrm{R}$ antagonist, NE-100, blocked the effects of (+)-pentazocine but not those of 4-IBP. The authors hypothesized the existence of subtypes of $\sigma_{1}$ Rs to explain the different results obtained with the different $\sigma_{1} R$ agonists. Because increased 5-HT neurotransmission might be implicated in neurotoxicity induced by some psychostimulants, like MDMA and methamphetamine, for example, it is worth noting that a recent paper shows that pretreatment with the non-selective $\sigma \mathrm{R}$ antagonist, AC 927, significantly attenuated 
methamphetamine-induced striatal 5-HT depletions, striatal 5-HT-transporter reductions, and hyperthermia [112]. These results strongly suggest that blockade of $\sigma$ Rs can alter 5-HT neurotransmission and this action might protect against methamphetamine-induced neurotoxicity.

\subsubsection{GABA Neurotransmission}

Pregnenolone and (+)-SKF 10,047 inhibit the GABA-dependent inhibitory postsynaptic currents in rat hippocampal cell cultures [113], and the effects were antagonized by haloperidol and BD 1063. The effects were also blocked by pertussis toxin, suggesting a presynaptic location of $\sigma$ Rs and their coupling with Gi/o proteins [113]. Because the hippocampus has a role in learning and memory, interactions of $\sigma \mathrm{R}$ and GABA systems such as those demonstrated by Mtchedlishvili and Kapur [113] suggest that circulating neurosteroids with affinity for $\sigma$ Rs might be involved in modulation of learning and memory [see 114]. In general, the inhibition of spontaneous release of GABA might facilitate release of other neurotransmitters throughout the CNS, altering the function of other neurotransmitter systems.

\section{Cocaine and $\sigma R s$}

\subsection{Binding Studies and Acute Toxicity}

Several years ago Sharkey et al. [115] reported that cocaine had affinity for $\sigma$ Rs. The affinity of cocaine was determined with $\left[{ }^{3} \mathrm{H}\right]$ haloperidol using $25 \mathrm{nM}$ of unlabeled spiperone to block the labeling by the radioligand of 5- $\mathrm{HT}_{2}$ and $\mathrm{D} 2$ receptors. The affinity of cocaine for the $\sigma \mathrm{R}$ was reported to be $6.7 \mu \mathrm{M}$. More recently the affinity of cocaine for $\sigma_{1}$ and $\sigma_{2}$ receptors was reported with the current conventional radioligands and assay conditions for these sites [56]. The affinity of cocaine for the $\sigma_{1} R$ using $\left[{ }^{3} \mathrm{H}\right](+)$-pentazocine was reported to be $5.19 \mu \mathrm{M}$. In addition, the affinity of cocaine for the $\sigma_{2} \mathrm{R}$ was reported to be $19.3 \mu \mathrm{M}$ using $\left[{ }^{3} \mathrm{H}\right] \mathrm{DTG}$ with excess (+)-pentazocine $(200 \mathrm{nM})$ to block the binding to $\sigma_{1}$ Rs.

Sharkey et al. [115] argued that concentrations in brain sufficient to bind to $\sigma$ Rs would be reached at high doses of cocaine that produce acute psychotic reactions in humans. However, the authors also argued that actions at $\sigma$ Rs were not likely to contribute to the reinforcing effects of cocaine that are obtained at lower doses. Seemingly consistent with the findings of Sharkey et al. a multiple regression analysis among potencies of cocaine-like agents to produce seizures or lethality indicated that a substantial amount of the variance for either effect was accounted for by binding to the 5-HT or DA transporters, respectively. However, $\sigma \mathrm{R}$ binding as well as binding at muscarinic sites appeared to attenuate seizure-producing or lethal effects of the cocaine-like drugs [116].

Several studies have examined more closely the interactions between cocaine and a large number of $\sigma \mathrm{R}$ ligands [see review by 1]. For example, the $\sigma \mathrm{R}$ antagonists, BD 1047 and LR172 blocked cocaine-induced seizures, lethality, and locomotor stimulation [117]. Other studies have found that the $\sigma \mathrm{R}$ agonist, DTG, enhanced the convulsive effects of low doses of cocaine that had no convulsive effects when administered alone and lowered the cocaine $\mathrm{LD}_{50}$ value [118]. Finally, antisense directed at area -97 to -77 after the initiation codon of a cloned cDNA sequence for $\sigma_{1}$ Rs from mouse was injected via indwelling cannulae to the lateral ventricles. Three infusions of $10 \mu \mathrm{g} / 5 \mathrm{~mL}$ were 
administered over a four-day period. This antisense treatment attenuated the convulsive and locomotor stimulant effects of cocaine whereas a mismatch sequence was relatively less active. In addition, the treatment decreased the $\mathrm{B}_{\max }$ for $\sigma \mathrm{R}$ binding by 38 to $45 \%$. The functional pharmacology therefore suggests that increased $\sigma \mathrm{R}$ activity enhances, whereas decreased $\sigma \mathrm{R}$ activity either by antagonist or antisense treatment, attenuates the effects of cocaine. Those functional results are difficult to reconcile with the statistical approach of Ritz and George [116] that suggests that the actions of cocaine-like compounds at $\sigma$ Rs diminish the seizure-producing and lethal effects of cocaine. Cocaine has been fairly well substantiated as a $\sigma \mathrm{R}$ agonist $[12,14]$. Whether the other "cocaine-like" compounds examined by Ritz and George [116] have $\sigma \mathrm{R}$ agonist or antagonist effects has not been established.

\subsection{Locomotor-Stimulant Effects}

The first study that established that $\sigma \mathrm{R}$ antagonists could block the locomotor stimulant effects of cocaine [119] examined the effects of BMY 14802 and rimcazole, and compared their effects to those of clozapine, haloperidol, and (+)-3-PPP. Both of the $\sigma \mathrm{R}$ antagonists blocked the locomotor stimulant effects of cocaine at doses that were inactive when administered alone. In contrast, the antagonism of the locomotor stimulant effects of cocaine produced by the DA receptor antagonists required doses that also decreased activity when administered alone (see also [120]). Similar results were reported by Okuyama et al. [121] with methamphetamine induced locomotor activity. Interestingly, the selective $\sigma \mathrm{R}$ antagonist, NE-100, was inactive in the latter study. Nonetheless, a substantial literature has indicated that antagonism of the locomotor effects of stimulant drugs is produced by a wide variety of selective $\sigma \mathrm{R}$ antagonists, such as BD 1063, and that the antagonism is similar to that produced for convulsions and lethality $[118,122]$. In addition, several $\sigma \mathrm{R}$ antagonists significantly attenuated the development of cocaine-induced locomotor sensitization [123,124]. The selective $\sigma_{1} R$ antagonist MS-377 also attenuated the sensitization to stereotyped behavior induced by methamphetamine [125].

The antagonism of locomotor effects of stimulant drugs poses the question of whether $\sigma \mathrm{R}$ agonists have stimulant effects of their own. The selective $\sigma_{1} \mathrm{R}$ agonist, (+)-pentazocine ( 1.0 to $\left.10.0 \mathrm{mg} / \mathrm{kg}\right), \mathrm{did}$ not affect locomotor activity in mice [126]. However, another study indicated relatively modest increases in locomotor activity produced by $32 \mathrm{mg} / \mathrm{kg}$ of (+)-pentazocine in rats [127]. Another selective $\sigma_{1} \mathrm{R}$ agonist, PRE-084, has been reported to have no effect on locomotor activity in mice up to doses of 10 [128] and $60 \mathrm{mg} / \mathrm{kg}$ [129]. The nonselective $\sigma \mathrm{R}$ agonist, DTG has been studied at doses up to $20 \mathrm{mg} / \mathrm{kg}$ and only decreased activity at the highest dose tested [130]. Despite its lack of locomotor stimulant effects of its own, DTG potentiated cocaine induced locomotor stimulant effects in rats [131]. Similarly, the $\sigma \mathrm{R}$ agonist, SA 4503, which has been reported to be $\sim 14-$ [132] to $\sim 100$-fold [133] selective for the $\sigma_{1} \mathrm{R}$ over the $\sigma_{2} \mathrm{R}$, only decreased locomotor activity in rats across the range of behaviorally active doses $[134,135]$. Thus it appears that $\sigma \mathrm{R}$ agonists are relatively devoid of locomotor stimulant effects.

\subsection{Discriminative Stimulus Effects}

Several studies have examined the discriminative-stimulus (subjective) effects of $\sigma \mathrm{R}$ agonists. In these studies, the subject is trained using operant conditioning techniques to emit one response (intermittently reinforced typically with food pellets) after administration of vehicle and a different 
response after administration of a behaviorally active drug. Once subjects are trained to some level of accuracy, typically greater than $90 \%$ of responses appropriate to the vehicle and "training" drug conditions, they can be tested with various treatments to assess the degree to which the treatment produces or modifies the discriminative effects of the training drug (see [136] for a full description of the technique). Typically drugs that share pharmacological mechanism with the training drug will produce a response from the subject similar, if not identical, to $(>90 \%$ training drug-appropriate responding) the training drug. For example, in rats trained in a cocaine-discrimination procedure, the cocaine analog, WIN 35,428, which has approximately 10-fold higher affinity than cocaine for the DAT is 10 -fold more potent than cocaine and at the appropriate dose produces $\sim 100 \%$ cocaine-appropriate responding [e.g. 137].

Studies of the discriminative stimulus effects of $\sigma \mathrm{R}$ agonists were hampered initially by lack of clear indications of which compounds had the selectivity necessary to serve as a standard against which other compounds could be compared. Initial studies with dextromethorphan [138,139] and $(+)$-SKF 10,047 [140,141] did not distinguish between phencyclidine (PCP)-like compounds and $\sigma \mathrm{R}$ agonists. Singh et al. [142] examined the potential of several compounds with high affinity for the $\sigma \mathrm{R}$ to displace $\left[{ }^{3} \mathrm{H}\right] \mathrm{DTG}$ from CNS sites in ex vivo binding assays and to substitute for the discriminative effects of (+)-SKF 10,047. Racemic pentazocine (with a concomitant dose of naloxone to block its opioid effects) substituted for (+)-SKF 10,047, however the other compounds that displaced [ ${ }^{3}$ H]DTG were ineffective either as agonists or antagonists of $(+)$-SKF 10,047. In addition substitution was obtained with MK-801, a PCP receptor ligand with no appreciable affinity for the $\sigma \mathrm{R}$. The authors concluded that their results were consistent with an NMDA-receptor mediation of the discriminative-stimulus effects of (+)-SKF 10,047 and that there was no evidence for a role of $\sigma$ Rs in the discriminative stimulus effects of $(+)$-SKF 10,047. However, the results with pentazocine/naloxone combinations suggest that the conclusions be reconsidered.

Rats trained to discriminate between s.c. injections of DTG $(3.0 \mathrm{mg} / \mathrm{kg})$ and saline generalized fully or virtually fully to PCP and related drugs as well as various opioid receptor agonists and $(+)$-enantiomers of benzomorphans [143]. Additionally, a group of rats trained to discriminate saline from $2.0 \mathrm{mg} / \mathrm{kg}$ of PCP generalized completely to DTG. Thus the selectivity of DTG as a $\sigma \mathrm{R}$ radioligand, does not carry over to the behavioral effects of the drug. The disconnect between radioligand binding and behavioral outcomes requires further study.

Steinfels et al. [144] trained rats to discriminate $2.0 \mathrm{mg} / \mathrm{kg}$ of $(+)$-pentazocine from saline injections (s.c.). In studies of substitution, (+)-SKF 10,047 substituted fully for the training dose of $(+)$-pentazocine, which is consistent with radioligand binding studies that have indicated cross recognition of $(+)$-SKF 10,047 at PCP and $\sigma \mathrm{R}$ sites. However, PCP itself, which has low affinity for $\sigma \mathrm{R}$ sites, did not substitute for the training dose of $(+)$-pentazocine up to a dose of $6.0 \mathrm{mg} / \mathrm{kg}$ which had grossly observable pharmacological effects. This study, though limited, suggests that the discriminative-stimulus effects of $(+)$-pentazocine are different from those of PCP and further that this compound shows the most promise as a selective $\sigma \mathrm{R}$ agonist for in vivo studies.

In rats trained to discriminate s.c. injections of cocaine $(10 \mathrm{mg} / \mathrm{kg})$ from saline, DTG (1 and $10 \mathrm{mg} / \mathrm{kg}, 30 \mathrm{~min}$ before sessions) was no different from vehicle [145]. Similar results were reported by Cohen and Sanger [146] in abstract form. Additionally, the $\sigma_{1}$ R agonist, SA 4503, fully substituted for neither cocaine nor methamphetamine in rats trained with food reinforcement [134,135]. More 
recently both PRE-084 and DTG were examined in rats trained to discriminate cocaine (10 mg/kg, i.p.) from saline [147]. Neither compound substituted for cocaine when administered i.p., s.c. or i.v., 5 or $30 \mathrm{~min}$ before testing. In contrast, the standard DA uptake inhibitors, WIN 35,428 and methylphenidate, both fully reproduced cocaine-like discriminative-stimulus effects, as has been shown previously [137,148,149].

Other drug-discrimination studies demonstrated that the $\sigma_{1} R$ agonist, $(+)$-pentazocine, fully substituted in rats trained to discriminate ethanol [150] or buprenorphine [151]. These results suggest caution in the universal acceptance of $(+)$-penatzaocine as a selective $\sigma_{1} R$ ligand. However, the results are consistent with the suggestion of little, if any, overlap of the discriminative-stimulus effects of $\sigma \mathrm{R}$-agonists and stimulant compounds and therefore that the reinforcing effects of the $\sigma \mathrm{R}$ agonists [70] are not based on substantial overlap of the subjective effects of the two classes of drugs.

\subsection{Place Conditioning}

Place conditioning, or conditioned place preference as it is commonly known, is a procedure in which a drug is administered to the subject in a particular environment which typically consists of distinct tactile, visual, or olfactory stimuli. Vehicle is injected when the subject is in a different environment. The two environments are virtually always separate sections of a larger chamber. After several pairings of the environments with the respective injections (conditioning) the subject is given a test of the effectiveness of the conditioning by allowing it unrestricted access to either environment without drug administration. Virtually all of the commonly abused drugs produce a shift in the amount of time allocated within the two sections of the chamber such that the subject spends more time in the section paired with the drug [152].

An increase in time allocation compared to before conditioning is considered by many to be a measure of the reinforcing effect of the drug in place conditioning. It should be noted that this is a Pavlovian (or respondent) conditioning procedure because two sets of stimuli are paired: the stimuli that arise from being in the particular section of the chamber and those from the drug injection. In Pavlovian conditioning the pairing of two stimuli is considered reinforcement. This type of conditioning contrasts with self-administration procedures which involve operant conditioning in which a response of the subject is paired with a stimulus. In the self-administration procedure following a response with a stimulus, in this case those from the drug that is injected, is reinforcement if the response increases in probability. It is perhaps unfortunate, and potentially confusing, that the two procedures use the same term, reinforcement, to specify its inherent process. It may be a further source of confusion that in the place conditioning procedure the final test of the conditioning involves entry into a section of the chamber, which can be considered an operant response with the stimuli arising from entry into that section of the chamber as its consequence. It is no surprise that the two procedures, operant and Pavlovian conditioning, are comingled and difficult to un-entangle, even in the laboratory.

Several $\sigma R$ antagonists have been shown to block place conditioning produced by stimulant drugs, particularly cocaine. This effect was first reported by Romieu et al. [98] using mice. In that study, the $\sigma \mathrm{R}$ antagonists, NE-100 and BD 1047 (each at 1.0-10.0 mg/kg), dose-dependently blocked the place conditioning produced by cocaine $(20 \mathrm{mg} / \mathrm{kg})$ when administered in combination with cocaine during 
conditioning trials. The antagonists had no effects when administered alone. Additionally, in vivo administration of antisense oligodeoxynucleotides directed at the $\sigma_{1} \mathrm{R}$ blocked place conditioning by cocaine whereas a mismatch oligodeoxynucleotide was inactive.

In another study with mice [99], the effects of NE-100 and BD 1047 were replicated and extended to conditioning produced by another DAT inhibitor, BTCP. In addition to blocking the conditioning of a place preference, NE-100 (3.0, $10.0 \mathrm{mg} / \mathrm{kg})$ and BD $1047(1.0-10.0 \mathrm{mg} / \mathrm{kg})$ administered only on the post-conditioning test day decreased the amount of time spent on the cocaine-paired side of the chamber compared to that found with subjects given vehicle. Further, the $\sigma \mathrm{R}$ agonists, igmesine and PRE-084 (each at 10.0-60.0 $\mathrm{mg} / \mathrm{kg}$ ), were examined for their potential to produce place conditioning when administered alone. Neither of these $\sigma \mathrm{R}$ agonists had effects different from those of vehicle. The $\sigma \mathrm{R}$ agonist, SA 4503 studied at $3.0 \mathrm{mg} / \mathrm{kg}$, i.p. [153] and (+)-SKF 10,047 at doses from 1.0 to $4.0 \mathrm{mg} / \mathrm{kg}$ [154] were also inactive in producing a place conditioned effect in rats.

The neuroactive steroids, DHEA (5.0-20.0 mg/kg, s.c.) and pregnenolone (10, $20 \mathrm{mg} / \mathrm{kg}$, s.c.) were similarly inactive with regard to the induction of place conditioning [155]. Further, progesterone (10-40 mg/kg, s.c.) antagonized the place conditioning produced by cocaine $(20 \mathrm{mg} / \mathrm{kg}$, i.p.). Progesterone is a $\sigma \mathrm{R}$ antagonist whereas DHEA and pregnenolone are $\sigma \mathrm{R}$ agonists. Of course, as the authors noted, in addition to activity at $\sigma$ Rs each of these neuroactive steroids has effects on other systems. Nonetheless, these results are consistent with the general observation that $\sigma \mathrm{R}$ antagonists block the place conditioning induced by stimulant drugs but that $\sigma \mathrm{R}$ agonists themselves are ineffective for the induction of place conditioning.

The place conditioning data suggest that actions mediated by $\sigma$ Rs are necessary for cocaine-induced place conditioning. However, as the agonists were inactive, activation of $\sigma$ Rs alone is not a sufficient condition for place conditioning. The results with place conditioning are similar to results described above for the stimulant-induced stimulation of locomotor activity. The $\sigma \mathrm{R}$ antagonists were effective in blocking both locomotor stimulation and place conditioning produced by stimulant drugs. On the other hand, $\sigma \mathrm{R}$ agonists by themselves were inactive in inducing the effect that their antagonists were effective in blocking.

\subsection{Self Administration}

In an early study, Slifer and Balster [156] compared the reinforcing effects of the stereoisomers of the 6,7-benzomorphans, SKF 10,047 and cyclazocine, to those of PCP in rhesus monkeys trained to self administer cocaine under an fixed ratio (FR) 10 schedule of reinforcement. Neither the racemic forms nor the (-)-enantiomers of SKF 10,047 or cyclazocine were self administered at rates of response greater than those maintained by vehicle. In contrast, both $(+)$-SKF 10,047 and $(+)$-cyclazocine were self administered, with the maximal response rates maintained comparable to those maintained by either PCP or cocaine. At the time of the study, the distinction had not yet been conclusively made between $\sigma$ Rs and the PCP binding site. Because the drugs were not selective, the effects obtained were interpreted in terms of PCP-like effects of the $(+)$-enantiomers. Nonetheless, it remains possible that agonist actions at $\sigma$ Rs may have contributed to the self administration of both $(+)$-SKF 10,047 and (+)-cyclazocine. Because cocaine appears to act as an agonist at $\sigma \mathrm{Rs,} \mathrm{a}$ 
reinterpretation of these findings as involving $\sigma$ Rs suggests that the reinforcing effects of cocaine could be altered by $\sigma$ Rs antagonists.

More recently Martin-Fardon et al. [100] examined the effect of BD 1047 on cocaine self administration in rats. In that study, BD 1047 pretreatment did not affect cocaine self administration under an FR 5-response schedule, and was similarly ineffective on responding reinforced with sweetened-condensed milk in another group of rats. The authors also examined the effects of BD 1047 under a "reinstatement" procedure. This procedure has become popular as several authors have asserted that it is a valid model of relapse to drug taking [for a discussion of the merits of the assertion see 157]. Under the reinstatement procedure after training subjects to self administer cocaine the responding is then extinguished (responses no longer produce cocaine injections). Subsequently, conditions are imposed that increase the response rates above the low levels achieved during extinction (reinstatement). In the study by Martin-Fardon and colleagues, a stimulus previously associated with availability of cocaine self administration and absent during extinction was present during tests of "reinstatement." BD 1047 dose-dependently decreased reinstated response rates with significant effects at 20 and $30 \mathrm{mg} / \mathrm{kg}$. In contrast, reinstatement of responding previously reinforced with sweetened condensed milk was only decreased at $30 \mathrm{mg} / \mathrm{kg}$. The authors suggested that their findings support a role for $\sigma \mathrm{Rs}$ in regulating conditioned responses to cocaine-related stimuli and further suggest these receptors as a potential target for the development of drugs to treat cocaine abuse.

In examining the potential involvement of $\sigma$ Rs in the effects of cocaine we found, as in the study by Martin-Fardon et al. [100] that pretreatment of rats with $\sigma \mathrm{R}$ antagonists had no effect on cocaine self administration [70] (Figure 4A). However, pretreatment with $\sigma \mathrm{R}$ agonists produced a leftward shift in the cocaine dose-effect curve (Figure 4B). As these results resembled those obtained previously with standard DA uptake inhibitors, such as methylphenidate [158], it suggested that $\sigma \mathrm{R}$ agonists may have reinforcing effects of their own. Figure 4C shows that the $\sigma \mathrm{R}$ agonists, PRE-084 and DTG substituted for cocaine in rats trained to self administer cocaine, whereas $\sigma \mathrm{R}$ antagonists did not (data not shown).

That the $\sigma \mathrm{R}$ agonists would maintain self-administration behavior was surprising nonetheless. Though the study in monkeys by Slifer and Balster [156] had shown that the (+)-enantiomers of 6,7-benzomorphans would maintain self administration, that finding was interpreted as due to the PCP-like effects of the compounds. However, both DTG and PRE-084 are selective for $\sigma$ Rs over the PCP binding site indicating that the effect, at least in the study by Hiranita et al. [70] was due to their actions at $\sigma$ Rs. In addition, the self administration of the $\sigma \mathrm{R}$ agonists was antagonized by each of the $\sigma \mathrm{R}$ antagonists (BD 1008, BD 1047, BD 1063) studied, further substantiating that the self administration of the agonists was mediated by actions at $\sigma \mathrm{Rs}$.

The antagonism of the self administration of PRE-084 and DTG by the $\sigma \mathrm{R}$ antagonists also sheds light on other important aspects of the pharmacology of the $\sigma \mathrm{R}$ system. As mentioned above, it has been difficult to clearly establish what can be considered as an agonist or antagonist effect of a $\sigma \mathrm{R}$ ligand in preparations other than those involving $\sigma \mathrm{R}$ chaperone activity. The self-administration studies show in vivo actions that can be useful in characterizing the agonist or antagonist effects of $\sigma \mathrm{R}$ ligands. Additionally, the potency with which BD 1008, BD 1047 and BD 1063 blocked the self administration of the $\sigma \mathrm{R}$ agonists is illustrative. In the paper by Martin-Fardon and colleagues described above, a dose of $20 \mathrm{mg} / \mathrm{kg}$ of BD 1047 was necessary to block the reinstatement of cocaine self administration. That dose is approximately 10 -fold greater than the dose necessary to block the 
self administration of either PRE-084 or DTG, suggesting caution in interpreting the reversal of the reinstatement as a $\sigma \mathrm{R}$ antagonist effect. Finally, the $\sigma \mathrm{R}$ antagonists were all active as antagonists of PRE-084 and DTG self administration, but not cocaine self administration. Those findings suggest that the $\sigma \mathrm{R}$ is not involved in the primary effect of cocaine that leads to its abuse. This latter consideration is consistent with findings that actions at the DA are the key components for the reinforcing effects of cocaine.

Figure 4. Reinforcing effects of cocaine, its modification by $\sigma \mathrm{R}$ agonists and antagonists, and their substitution in rats trained to self administer cocaine.

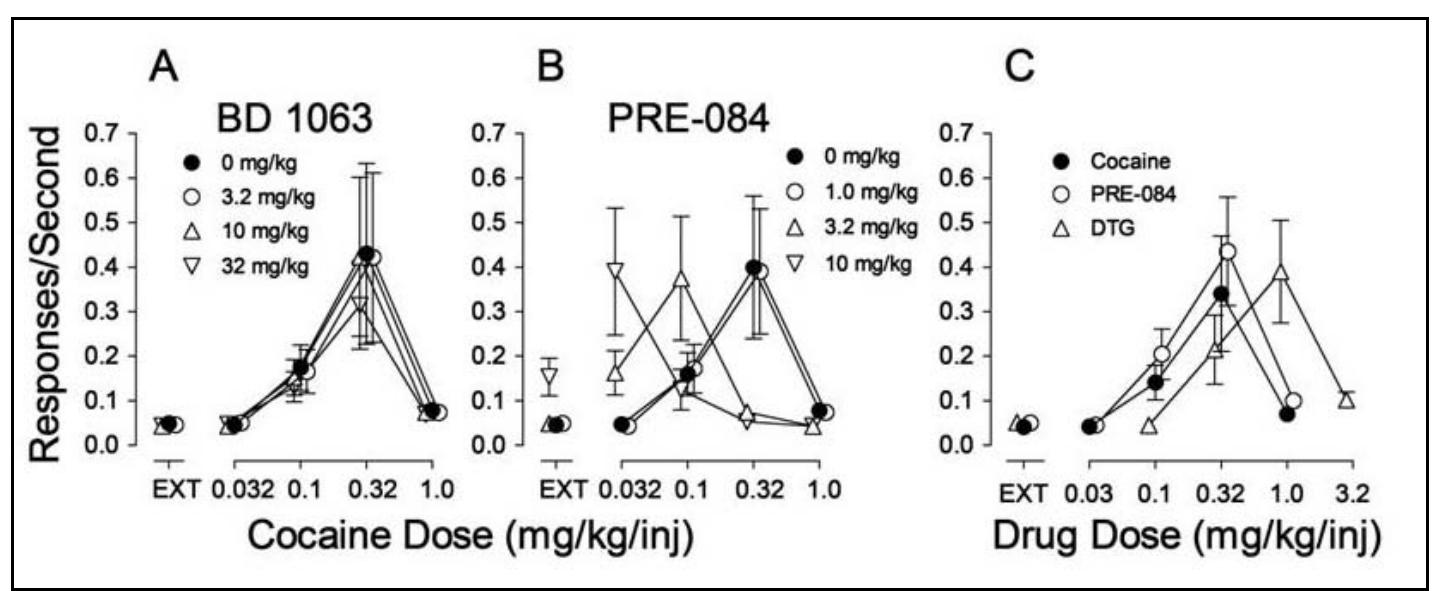

Ordinates: Responses per sec. Abscissae: Dose of cocaine or each substituted drug in $\mathrm{mg} / \mathrm{kg} /$ injection. Each point represents the mean \pm SEM $(\mathrm{N}=6)$. EXT: extinction (responses have no consequences). Panel A: Effects of pre-session treatments with the $\sigma \mathrm{R}$ antagonist, BD 1063 (3.2, 10 and $32 \mathrm{mg} / \mathrm{kg}$, i.p., $5 \mathrm{~min}$ before sessions) on cocaine self administration; Panel B: Effects of pre-session treatments with the $\sigma \mathrm{R}$ agonist PRE-084 (1.0, 3.2 and $10 \mathrm{mg} / \mathrm{kg}$, i.p., $30 \mathrm{~min}$ before sessions) on cocaine self administration. Panel C: Self administration of the $\sigma R$ agonists PRE-084 (open circles) and DTG (open triangles up) when substituted for cocaine.

\section{Effects of Chronic Cocaine Exposure}

It is useful to consider the differences between outcomes in the place conditioning and the self-administration procedures. Most drugs that are abused (e.g. cocaine) are active in both procedures. The frequent consistencies between outcomes in the two procedures lead many to consider them as interchangeable predictors of abuse liability, with the underlying assumption that similar mechanisms are involved in both procedures. However, as detailed above $\sigma \mathrm{R}$ antagonists block the acquisition of a cocaine-induced place conditioning (e.g. [98]), as well as the preferential time allocation after it is established (often referred to as its "expression," e.g. [99]). In addition, $\sigma \mathrm{R}$ agonists are inactive in producing place conditioning (e.g. [99]). In contrast, $\sigma \mathrm{R}$ antagonists are inactive in blocking or otherwise altering the self administration of cocaine whereas $\sigma \mathrm{R}$ agonists are self administered, at least in subjects with a history of cocaine self administration [70]. These differences reveal that self administration and place conditioning are not simply two procedures providing a "read out" of the same underlying reinforcement circuitry.

With specific regard to the $\sigma \mathrm{R}$ influences on place conditioning during its acquisition, the analogous experiment with cocaine self administration has not been conducted. In the two studies of $\sigma \mathrm{R}$ 
antagonists conducted to date the cocaine self administration was acquired prior to the testing. Nonetheless, the implication of the place conditioning studies is that there is a $\sigma \mathrm{R}$ involvement in some adaptation to the repeated administration of cocaine, suggesting studies of alterations of central function induced by cocaine and related to $\sigma$ Rs may shed light on cocaine abuse and chronic dependence.

\subsection{Gene Regulation and Transcription}

As described above, the acquisition of cocaine-induced place conditioning in mice was attenuated by co-treatment with $\sigma \mathrm{R}$ antagonists [98,99,155]. In the 2002 paper [99], Romieu et al. also examined the effect of cocaine exposure on $\sigma_{1} \mathrm{R}$ mRNA expression in the nucleus accumbens, caudate putamen, prefrontal cortex or cerebellum immediately after the subjects were tested for place conditioning. Comparative reverse transcriptase-polymerase chain reaction (RT-PCR) indicated a significant increase in $\sigma_{1} \mathrm{R}$ mRNA occurred after the cocaine treatment in the nucleus accumbens but not in the caudate putamen, prefrontal cortex, or cerebellum. The authors suggest that the change in $\sigma_{1} R$ expression is integral to the reinforcing effects of cocaine as evidenced in the place conditioning procedure.

Several studies have examined changes in various substrates induced by cocaine, which may be sensitive to modification by actions at $\sigma$ Rs. Matsumoto et al. [1] reported on microarray studies of gene expression in mice $20 \mathrm{~min}$ following administration of cocaine (at a dose that stimulates locomotor activity), BD 1063 (at a dose that blocks the cocaine effect) or the combination of the two compounds. Significant changes were confirmed using RT-PCR. Cocaine produced an up-regulation of 20 and down-regulation of 16 genes compared to tissue from non-treated mice. Of those, the $\sigma \mathrm{R}$ antagonist blocked cocaine-induced changes in three genes: fos-related antigen 2 (fra-2), GPCR 27, and ataxia telangiectasia murine homolog. The authors suggested that the changes in fra- 2 are noteworthy because cocaine stimulates the expression of other fos-related transcription factors. Because fra- 2 is stimulated by second messengers the authors reasoned that the cocaine antagonist effects of BD 1063 might be due to its blockade of the activation of the second messengers induced by cocaine. In further studies Liu et al. [159] used microarray techniques to assess the effects of cocaine and BD 1063 on the expression of six fos and jun genes: fra-2, c-fos, fosB, c-jun, junB and junD. Cocaine increased the expression of fra- 2 and junD, but only the alteration in fra- 2 was blocked by co-administration of BD 1063. Further, the increases in fra-2 were followed by a later up-regulation of $\sigma_{1} \operatorname{Rs}[159]$.

\subsection{Relation of Gene Expression Effects to Behavioral Effects}

The linkage of the molecular effects described above to behavioral outcomes is beginning to be elucidated. Romieu et al. [99] were the first to report changes in gene expression related to repeated cocaine treatment in a place conditioning procedure. In that study, repeated cocaine treatment increased expression of $\sigma_{1} \mathrm{Rs}$ in the NAC, but not in the caudate putamen, prefrontal cortex, or cerebellum. This regional selectivity suggests the importance of the adaptive change in $\sigma_{1}$ Rs for the effects of cocaine in place conditioning. 
Liu and Matsumoto [160] confirmed the increases in locomotor activity over 15 days of treatment with cocaine $(10 \mathrm{mg} / \mathrm{kg})$. The authors also examined fra- 2 and $\sigma_{1} \mathrm{R}$ gene expression (using RT-PCR) and proteins (Western blots). Along with locomotor activity, fra-2 and $\sigma_{1} R$ genes and proteins increased with cocaine exposure. Further, the $\sigma \mathrm{R}$ antagonist, BD 1063, attenuated the gene and gene product changes as well as the locomotor sensitization produced by cocaine [160]. The authors concluded that repeated cocaine exposure produces increases in fra- 2 and $\sigma_{1}$ Rs which underlie the sensitization produced.

The self administration of methamphetamine has also been shown to alter $\sigma_{1} \mathrm{R}$ systems. In one study [161], rats self administered methamphetamine $(0.1 \mathrm{mg} / \mathrm{kg} /$ injection $)$ whereas one of two other groups received the same dose of methamphetamine with frequencies matched to the group that self administered the drug (yoked control). A second control group received saline injections with a matching frequency. Western blots revealed a $50 \%$ increase in $\sigma_{1} \mathrm{R}$ protein in midbrain and Northern blots showed decreases in $\sigma_{1} \mathrm{R}$ mRNA levels in frontal cortex and increases in hippocampus of subjects actively self administering methamphetamine, but not in the yoked methamphetamine-exposed or saline-control rats. The authors concluded that increases in $\sigma_{1}$ Rs contribute to the reinforcing effects of methamphetamine. A previous study [162] found a down-regulation of DA D2 autoreceptors with methamphetamine self administration. The authors speculated that the down-regulation of DA D2 autoreceptors would increase adenylate cyclase, and consequently protein kinase A (PKA) activity. As one part of this report the authors showed that dibutyryl cAMP which activates PKA increased $\sigma_{1} R$ protein level in NG-108 cells compared to vehicle exposed cells. Therefore, the results suggest that $\sigma_{1} \mathrm{R}$ up-regulation, induced by methamphetamine self administration is mediated by increased PKA activity due to DA D2 autoreceptor down-regulation.

In a subsequent study [163], methamphetamine, whether self administered or passively received, significantly elevated $\sigma_{1}$ Rs, as well as the endoplasmic reticulum chaperones BiP and calreticulin in the ventral tegmental area and substantia nigra. In the olfactory bulb, however, only the $\sigma_{1} \mathrm{R}$ chaperone was increased, and this increase occurred only in rats that actively self administered methamphetamine. Also in the olfactory bulb $\sigma_{1}$ Rs were co-localized with DA D1 receptors. The authors concluded that methamphetamine whether administered actively or passively induced ER stress which precipitates the activity of ER chaperones. However, the changes seen only in rats that actively self administered methamphetamine suggests that D1 and $\sigma_{1}$ Rs in the olfactory bulb might play an important role in the self administration of methamphetamine. The relation between DA D1 and $\sigma_{1}$ Rs in the olfactory bulb is particularly interesting in light of findings that a D1 agonist, (+)-SKF 38393, is more effective than cocaine in regulating $\sigma_{1}$ Rs in SVG cells [164]. Curiously in that study $\sigma_{1}$ Rs were down- rather than up-regulated. Another linkage between D1 and $\sigma_{1}$ Rs comes from studies suggesting that these proteins form heterodimers [28]. Finally, the up-regulation of $\sigma_{1}$ Rs by cocaine administration in vivo does not occur in mice with a genetic deletion of DA D1 receptors [165].

\section{Summary and Conclusions}

As the studies of gene regulation demonstrate, there is substantial evidence of the involvement of $\sigma_{1}$ Rs in behavioral effects of stimulant drugs. Studies of the time course of effects suggest specific changes in fra- 2 are followed by an up regulation of $\sigma_{1}$ Rs, and that those changes are reasonably well 
correlated with behavioral changes. Causality on the other hand is obviously difficult to conclusively demonstrate. The changes in behavior occur exceedingly rapidly. As a consequence, improved time resolution of demonstrated genetic changes may help determine which brain regions are the most critical for the demonstrated effects. In addition, the application of technological advances allowing direct manipulation of genetic changes will provide tests of hypotheses regarding the importance of the regulation of particular genes. As the first section of this paper shows, substantial and significant advances have accrued in the understanding of the cellular biology of $\sigma$ Rs. These advances provide a blue print for further studies that are focused on the cellular mechanisms involved in the changes that accompany exposure to stimulant drugs.

It is likely important to note that the most studied (with regard to $\sigma \mathrm{R}$ influence) behavioral outcomes of stimulant administration are locomotor activity and place conditioning. These procedures have exhibited a remarkable similarity in their $\sigma \mathrm{R}$ pharmacology. In particular, the behavioral effects of stimulants under both procedures are sensitive to $\sigma \mathrm{R}$ antagonism. This sensitivity appears to be extant in both the acquisition and the manifestation of stimulant-induced locomotor sensitization and place conditioning. Further, while $\sigma \mathrm{R}$ antagonists can block the effects of stimulants, $\sigma \mathrm{R}$ agonists are inactive on their own, though may increase the effects of stimulants. On the other hand, the $\sigma \mathrm{R}$ pharmacology of stimulant self administration has been less well studied. However, current evidence suggests that it is different from what has been elucidated so far with the other behavioral procedures. For example, cocaine self administration is not altered by $\sigma \mathrm{R}$ antagonist administration, whereas both place conditioning and sensitized locomotor activation are readily blocked by $\sigma \mathrm{R}$ antagonists. Whether the acquisition of cocaine self administration is sensitive to $\sigma \mathrm{R}$ antagonism has not yet been determined. In contrast to the negative findings in place conditioning, $\sigma \mathrm{R}$ agonists alone are self administered, and their administration also shifts the stimulant self-administration dose-effect curves leftward. The above differences in the outcomes with different behavioral procedures indicate that the resultant effects do not represent interchangeable readouts of a singular neurobiological mechanism.

Clearly a more thorough characterization of the behavioral and cellular pharmacology of $\sigma \mathrm{R}$ agonists and antagonists, both alone and in combination with stimulant drugs, will help to elucidate the role of $\sigma \mathrm{Rs}$ in the behavioral changes that accompany exposure to stimulant drugs. As we delve more deeply into the $\sigma \mathrm{R}$ cellular mechanisms involved in the effects of stimulant drugs, it is important to remain cognizant of the differences in behavioral outcomes which point to important differences in their underlying mechanisms which may have implications for an ultimate application of this knowledge in the development of medications to treat stimulant abuse.

\section{Appendix 1: Non-Standard Abbreviations and Relevant Compounds}

4-IBP: 4-(N-benzylpiperidin-4-yl)-4-iodobenzamide

(+)-MR200: (+)-methyl 2-[[4-(4-chlorophenyl)-4-hydroxypiperidin-1-yl]methyl]-1-phenylcyclopropanecarboxylate oxalate

(+)-3-PPP: 3-(3-hydroxyphenyl)-N-n-propylpiperone $\mathrm{HCl}$

AC 927: N-phenethylpiperidine oxalate

BD 1008: N-[2-(3,4-dichlorophenyl)ethyl]-N-methyl-2-(1-pyrrolidinyl)ethylamine dihydrobromide BD 1047: N-[2-(3,4-dichlorophenyl)ethyl]-N-methyl-2-(dimethylamino)ethylamine dihydrobromide 
BD 1063: 1-[2-(3,4-dichlorophenyl)ethyl]-4-methylpiperazine dihydrochloride

BMY 14802: $\alpha$-(4-fluorophenyl)-4-(5-fluoro-2-pyrimidinyl)-1-piperazinebutanol

BTCP: N-[1-(2-benzo(b)thiophenyl) cyclohexyl]piperidine

$\mathrm{Ca} 2+$ : Calcium ion

DA: dopamine

DAT: dopamine transporter

DHEA: dehydroepiandrosterone (3$\beta$-hydroxy-5-androsten-17-one), $\sigma \mathrm{R}$ agonist

DTG: 1,3-di-o-tolylguanidine

ER: endoplasmic reticulum

EXT: extinction

FR: fixed ratio

igmesine: $\sigma \mathrm{R}$ agonist

Inj: injection

LR172: N-[2-(3,4-dichlorophenyl)ethyl]-N-methyl-2-(1-homopiperidinyl)ethylamine

MAM: mitochondria-associated ER membrane

MS-377: (R)-(+)-1-(4-chlorophenyl)-3-[4-(2-methoxyethyl)piperazin-1-yl]methyl-2-

pyrrolidinone L-tartrate

NAC: nucleus accumbens

NE: norepinephrine

NE-100: N,N-dipropyl-2-[4-methoxy-3-(2-phenylethoxy)phenyl]ethylamine monohydrochloride

NET: norepinephrine transporter

PKA: protein kinase A

PCP: phencyclidine

PRE-084: 2-(4-Morpholinethyl) 1-phenylcyclohexane-1-carboxylate hydrochloride

Pregnenolone: 3 $\beta$-hydroxy-5-pregnen-20-one, $\sigma \mathrm{R}$ agonist

Progesterone: 4-pregnene-3,20-dione, $\sigma \mathrm{R}$ antagonist

Rimcazole: 9-[3-(cis-3,5-dimethyle-1-piperazinyl)propyl]-9H-carbazole dihydrochloride

SERT: serotonin transporter

SKF 10,047: $N$-allylnormetazocine

WIN 35,428: (-)-2ß-carbomethoxy-3ß-(4-fluorophenyl)tropane

$\sigma_{1}$ R: Sigma 1 receptor

$\sigma_{2} \mathrm{R}$ : Sigma 2 receptor

$\sigma R$ : Sigma receptor

\section{References}

1. Matsumoto, R.R.; Liu, Y.; Lerner, M.; Howard, E.W.; Brackett, D.J. Sigma receptors: Potential medications development target for anti-cocaine agents. Eur. J. Pharmacol. 2003, 469, 1-12.

2. Guitart, X.; Codony, X.; Monroy, X. Sigma receptors: Biology and therapeutic potential. Psychopharmacology (Berl) 2004, 174, 301-319.

3. Maurice, T.; Romieu, P. Involvement of the sigmal receptor in the appetitive effects of cocaine. Pharmacopsychiatry 2004, 37(Suppl), S198-S207. 
4. Leonard, B.E. Sigma receptors and sigma ligands: background to a pharmacological enigma. Pharmacopsychiatry 2004, 37(Suppl), S166-S170.

5. Skuza, G.; Wedzony, K. Behavioral pharmacology of sigma-ligands. Pharmacopsychiatry 2004, 37(Suppl), S183-S188.

6. Martin, W.R.; Eades, C.G.; Thompson, J.A.; Huppler, R.E.; Gilbert, P.E. The effects of morphine- and nalorphine-like drugs in the nondependent and morphine-dependent chronic spinal dog. J. Pharmacol. Exp. Ther. 1976, 197, 517-532.

7. Vaupel, D.B. Naltrexone fails to antagonize the sigma effects of PCP and SKF 10,047 in the dog. Eur. J. Pharmacol. 1983, 92, 269-274.

8. Quirion, R.; Hammer, R.P., Jr.; Herkenham, M.; Pert, C.B. Phencyclidine (angel dust)/sigma "opiate" receptor: Visualization by tritium-sensitive film. Proc. Natl. Acad. Sci. USA 1981, 78, 5881-5885.

9. Holtzman, S.G. Phencyclidine-like discriminative stimulus properties of opioids in the squirrel monkey. Psychopharmacology (Berl) 1982, 77, 295-300.

10. Wong, E.H.; Kemp, J.A.; Priestley, T.; Knight, A.R.; Woodruff, G.N.; Iversen, L.L. The anticonvulsant MK-801 is a potent N-methyl-D-aspartate antagonist. Proc. Natl. Acad. Sci. USA 1986, 83, 7104-7108.

11. Weber, E.; Sonders, M.; Quarum, M.; McLean, S.; Pou, S.; Keana, J.F. 1,3-Di(2-[5-3H]tolyl)guanidine: A selective ligand that labels sigma-type receptors for psychotomimetic opiates and antipsychotic drugs. Proc. Natl. Acad. Sci. US A 1986, 83, 8784-8788.

12. Matsumoto, R.R.; Bowen, W.D.; Su, T.P. Sigma Receptors: Chemistry, Cell Biology and Clinical Implications. Springer Science + Business Media, LLC: New York, NY, USA, 2007.

13. Maurice, T.; Su, T.P. The pharmacology of sigma-1 receptors. Pharmacol. Ther. 2009, 124, 1 95-206.

14. Hayashi, T.; Su, T.P. Sigma-1 receptor chaperones at the ER-mitochondrion interface regulate $\mathrm{Ca}(2+)$ signaling and cell survival. Cell 2007, 131, 596-610.

15. Pal, A.; Chu, U.B.; Ramachandran, S.; Grawoig, D.; Guo, L.W.; Hajipour, A.R.; Ruoho, A.E. Juxtaposition of the steroid binding domain-like I and II regions constitutes a ligand binding site in the sigma-1 receptor. J. Biol. Chem. 2008, 283, 19646-19656.

16. Su, T.P.; Hayashi, T.; Maurice, T.; Buch, S.; Ruoho, A.E. The sigma-1 receptor chaperone as an inter-organelle signaling modulator. Trends Pharmacol. Sci. 2010, 31, 557-566.

17. Hanner, M.; Moebius, F.F.; Flandorfer, A.; Knaus, H.G.; Striessnig, J.; Kempner, E.; Glossmann, H. Purification, molecular cloning, and expression of the mammalian sigma1-binding site. Proc. Natl. Acad. Sci. USA 1996, 93, 8072-8077.

18. Hayashi, T.; Tsai, S.Y.; Mori, T.; Fujimoto, M.; Su, T.P. Targeting ligand-operated chaperone sigma-1 receptors in the treatment of neuropsychiatric disorders. Expert Opin. Ther. Targets 2011, 15, 557-577.

19. Ha, Y.; Dun, Y.; Thangaraju, M.; Duplantier, J.; Dong, Z.; Liu, K.; Ganapathy, V.; Smith, S.B. Sigma receptor 1 modulates endoplasmic reticulum stress in retinal neurons. Invest. Ophthalmol. Vis. Sci. 2011, 52, 527-540.

20. Martin, W.R. Pharmacology of opioids. Pharmacol. Rev. 1983, 35, 283-323. 
21. Itzhak, Y. Multiple affinity binding states of the sigma receptor: Effect of GTP-binding protein-modifying agents. Mol. Pharmacol. 1989, 36, 512-517.

22. Hayashi, T.; Rizzuto, R.; Hajnoczky, G.; Su, T.P. MAM: More than just a housekeeper. Trends Cell Biol. 2009, 19, 81-88.

23. Rizzuto, R.; Pinton, P.; Brini, M.; Chiesa, A.; Filippin, L.; Pozzan, T. Mitochondria as biosensors of calcium microdomains. Cell Calcium 1999, 26, 193-199.

24. Mavlyutov, T.A.; Epstein, M.L.; Andersen, K.A.; Ziskind-Conhaim, L.; Ruoho, A.E. The sigma-1 receptor is enriched in postsynaptic sites of C-terminals in mouse motoneurons. An anatomical and behavioral study. Neuroscience 2010, 167, 247-255.

25. Aydar, E.; Palmer, C.P.; Klyachko, V.A.; Jackson, M.B. The sigma receptor as a ligand-regulated auxiliary potassium channel subunit. Neuron 2002, 34, 399-410.

26. Fontanilla, D.; Johannessen, M.; Hajipour, A.R.; Cozzi, N.V.; Jackson, M.B.; Ruoho, A.E. The hallucinogen N,N-dimethyltryptamine (DMT) is an endogenous sigma-1 receptor regulator. Science 2009, 323, 934-937.

27. Kim, F.J.; Kovalyshyn, I.; Burgman, M.; Neilan, C.; Chien, C.C.; Pasternak, G.W. Sigma 1 receptor modulation of G-protein-coupled receptor signaling: Potentiation of opioid transduction independent from receptor binding. Mol. Pharmacol. 2010, 77, 695-703.

28. Navarro, G.; Moreno, E.; Aymerich, M.; Marcellino, D.; McCormick, P.J.; Mallol, J.; Cortes, A.; Casado, V.; Canela, E.I.; Ortiz, J.; et al. Direct involvement of sigma-1 receptors in the dopamine D1 receptor-mediated effects of cocaine. Proc. Natl. Acad. Sci. USA 2010, 107, 18676-18681.

29. Martina, M.; Turcotte, M.E.; Halman, S.; Bergeron, R. The sigma-1 receptor modulates NMDA receptor synaptic transmission and plasticity via SK channels in rat hippocampus. J. Physiol. 2007, 578, 143-157.

30. Morin-Surun, M.P.; Collin, T.; Denavit-Saubie, M.; Baulieu, E.E.; Monnet, F.P. Intracellular sigmal receptor modulates phospholipase $\mathrm{C}$ and protein kinase $\mathrm{C}$ activities in the brainstem. Proc. Natl. Acad. Sci. USA 1999, 96, 8196-8199.

31. Hayashi, T.; Su, T.P. Intracellular dynamics of sigma-1 receptors (sigma(1) binding sites) in NG108-15 cells. J. Pharmacol. Exp. Ther. 2003, 306, 726-733.

32. Hayashi, T.; Fujimoto, M. Detergent-resistant microdomains determine the localization of sigma-1 receptors to the endoplasmic reticulum-mitochondria junction. Mol. Pharmacol. 2010, 77, 517-528.

33. Hayashi, T.; Su, T.P. Subcellular Localization and Intracellular Dynamics of Sigma-1 Receptors. In Sigma Receptors: Chemistry, Cell Biology and Clinical Implications; Matsumoto, R.R.; Bowen, W.D.; Su, T.-P.; Eds; Springer: New York, NY, USA, 2007; pp. 151-164.

34. Hayashi, T.; Su, T.P. Sigma-1 receptors (sigma(1) binding sites) form raft-like microdomains and target lipid droplets on the endoplasmic reticulum: Roles in endoplasmic reticulum lipid compartmentalization and export. J. Pharmacol. Exp. Ther. 2003, 306, 718-725.

35. Palmer, C.P.; Mahen, R.; Schnell, E.; Djamgoz, M.B.; Aydar, E. Sigma-1 receptors bind cholesterol and remodel lipid rafts in breast cancer cell lines. Cancer Res. 2007, 67, 11166-11175.

36. Sun, F.C.; Wei, S.; Li, C.W.; Chang, Y.S.; Chao, C.C.; Lai, Y.K. Localization of GRP78 to mitochondria under the unfolded protein response. Biochem. J. 2006, 396, 31-39. 
37. Johnson, S.; Michalak, M.; Opas, M.; Eggleton, P. The ins and outs of calreticulin: From the ER lumen to the extracellular space. Trends Cell Biol. 2001, 11, 122-129.

38. Crofts, A.J.; Leborgne-Castel, N.; Pesca, M.; Vitale, A.; Denecke, J. BiP and calreticulin form an abundant complex that is independent of endoplasmic reticulum stress. Plant Cell 1998, 10, 813-824.

39. Sharma, P.; Ignatchenko, V.; Grace, K.; Ursprung, C.; Kislinger, T.; Gramolini, A.O. Endoplasmic reticulum protein targeting of phospholamban: A common role for an N-terminal di-arginine motif in ER retention? PLoS One 2010, 5, e11496.

40. Yang, W.; Zheng, C.; Song, Q.; Yang, X.; Qiu, S.; Liu, C.; Chen, Z.; Duan, S.; Luo, J. A three amino acid tail following the TM4 region of the N-methyl-D-aspartate receptor (NR) 2 subunits is sufficient to overcome endoplasmic reticulum retention of NR1-1a subunit. J. Biol. Chem. 2007, 282, 9269-9278.

41. Schroder, M.; Kaufman, R.J. The mammalian unfolded protein response. Annu. Rev. Biochem. 2005, 74, 739-789.

42. Fujimoto, M.; Hayashi, T.; Urfer, R.; Mita, S.; Su, T.-P. Sigma-1 receptor agonist cutamesine enhances the secretion of brain-derived neurotrophic factor from neuroblastoma cells. Soc. Neurosci. Abst. 2010, 136.1/D33.

43. Sprong, H.; van der Sluijs, P.; van Meer, G. How proteins move lipids and lipids move proteins. Nat. Rev. Mol. Cell Biol. 2001, 2, 504-513.

44. Takebayashi, M.; Hayashi, T.; Su, T.P. Sigma-1 receptors potentiate epidermal growth factor signaling towards neuritogenesis in PC12 cells: Potential relation to lipid raft reconstitution. Synapse 2004, 53, 90-103.

45. Hayashi, T.; Su, T.P. The potential role of sigma-1 receptors in lipid transport and lipid raft reconstitution in the brain: Implication for drug abuse. Life Sci. 2005, 77, 1612-1624.

46. Aridor, M.; Guzik, A.K.; Bielli, A.; Fish, K.N. Endoplasmic reticulum export site formation and function in dendrites. J. Neurosci. 2004, 24, 3770-3776.

47. Mu, Y.; Otsuka, T.; Horton, A.C.; Scott, D.B.; Ehlers, M.D. Activity-dependent mRNA splicing controls ER export and synaptic delivery of NMDA receptors. Neuron 2003, 40, 581-594.

48. Takebayashi, M.; Hayashi, T.; Su, T.P. Nerve growth factor-induced neurite sprouting in PC12 cells involves sigma-1 receptors: Implications for antidepressants. J. Pharmacol. Exp. Ther. 2002, $303,1227-1237$.

49. Nishimura, T.; Ishima, T.; Iyo, M.; Hashimoto, K. Potentiation of nerve growth factor-induced neurite outgrowth by fluvoxamine: Role of sigma-1 receptors, IP3 receptors and cellular signaling pathways. PLoS One 2008, 3, e2558.

50. Tsai, S.Y.; Hayashi, T.; Harvey, B.K.; Wang, Y.; Wu, W.W.; Shen, R.F.; Zhang, Y.; Becker, K.G.; Hoffer, B.J.; Su, T.P. Sigma-1 receptors regulate hippocampal dendritic spine formation via a free radical-sensitive mechanism involving Rac1xGTP pathway. Proc. Natl. Acad. Sci. USA 2009, 106, 22468-22473.

51. Tsai, S.Y.; Hayashi, T.; Zhang, Y.; Becker, K.G.; Su, T.-P. Insights to the Sigma-1 receptor chaperone's cellular functions: A microarray report. Soc. Neurosci. Abstr. 2010, 136, 136.21/E11.

52. Walker, J.M.; Bowen, W.D.; Walker, F.O.; Matsumoto, R.R.; de Costa, B.; Rice, K.C. Sigma receptors: Biology and function. Pharmacol. Rev. 1990, 42, 355-402. 
53. de Costa, B.R.; Bowen, W.D.; Hellewell, S.B.; Walker, J.M.; Thurkauf, A.; Jacobson, A.E.; Rice, K.C. Synthesis and evaluation of optically pure $[3 \mathrm{H}]-(+)$-pentazocine, a highly potent and selective radioligand for sigma receptors. FEBS Lett. 1989, 251, 53-58.

54. Bowen, W.D.; Tolentino, P.J.; Kirschner, B.N.; Varghese, P.; de Costa, B.R.; Rice, K.C. Sigma receptors and signal transduction: Negative modulation of signaling through phosphoinositide-linked receptor systems. NIDA Res. Monogr. 1993, 133, 69-93.

55. Matsumoto, R.R.; Pouw, B.; Mack, A.L.; Daniels, A.; Coop, A. Effects of UMB24 and (+/-)-SM 21, putative sigma2-preferring antagonists, on behavioral toxic and stimulant effects of cocaine in mice. Pharmacol. Biochem. Behav. 2007, 86, 86-91.

56. Garcés-Ramírez, L.; Green, J.; Hiranita, T.; Kopajtic, T.; Mereu, M.; Thomas, A.; Mesangeau, C.; Narayanan, S.; McCurdy, C.; Katz, J.; et al. Sigma receptor agonists: Receptor binding and effects on mesolimbic dopamine neurotransmission assessed by microdialysis in rats. Biol. Psychiatry 2011, 69, 208-217.

57. Su, T.P. Sigma receptors. Putative links between nervous, endocrine and immune systems. Eur. J. Biochem. 1991, 200, 633-642.

58. Booth, R.G.; Wyrick, S.D.; Baldessarini, R.J.; Kula, N.S.; Myers, A.M.; Mailman, R.B. New sigma-like receptor recognized by novel phenylaminotetralins: Ligand binding and functional studies. Mol. Pharmacol. 1993, 44, 1232-1239.

59. Enomoto, R.; Ogita, K.; Yoneda, Y. Multiplicity of [3H]1,3-di-o-tolylguanidine binding sites with low affinity for haloperidol in rat brain. Biol. Pharm. Bull. 1993, 16, 989-996.

60. Vilner, B.J.; John, C.S.; Bowen, W.D. Sigma-1 and sigma-2 receptors are expressed in a wide variety of human and rodent tumor cell lines. Cancer Res. 1995, 55, 408-413.

61. Gundlach, A.L.; Largent, B.L.; Snyder, S.H. Autoradiographic localization of sigma receptor binding sites in guinea pig and rat central nervous system with $(+) 3 \mathrm{H}-3-(3$-hydroxyphenyl)-N-(1propyl)piperidine. J. Neurosci. 1986, 6, 1757-1770.

62. Gonzalez-Alvear, G.M.; Werling, L.L. Regulation of [3H]dopamine release from rat striatal slices by sigma receptor ligands. J. Pharmacol. Exp. Ther. 1994, 271, 212-219.

63. Imperato, A.; Tanda, G.; Frau, R.; di Chiara, G. Pharmacological profile of dopamine receptor agonists as studied by brain dialysis in behaving rats. J. Pharmacol. Exp. Ther. 1988, 245, 257-264.

64. Kanzaki, A.; Okumura, K.; Ujike, H.; Tsuchida, K.; Akiyama, K.; Otsuki, S. BMY-14802 reverses the reduction of striatal dopamine release induced by $(+)-3-[3-h y d r o x y p h e n y l]-N-(1-$ propyl)piperidine. J. Neural. Transm. Gen. Sect. 1992, 90, 137-144.

65. Gudelsky, G.A. Effects of sigma receptor ligands on the extracellular concentration of dopamine in the striatum and prefrontal cortex of the rat. Eur. J. Pharmacol. 1995, 286, 223-228.

66. Gudelsky, G.A. Biphasic effect of sigma receptor ligands on the extracellular concentration of dopamine in the striatum of the rat. J. Neural. Transm. 1999, 106, 849-856.

67. Moison, D.; de Deurwaerdere, P.; Cagnotto, A.; Marrazzo, A.; Prezzavento, O.; Ronsisvalle, G.; Mennini, T.; Spampinato, U. Intrastriatal administration of sigma ligands inhibits basal dopamine release in vivo. Neuropharmacology 2003, 45, 945-953. 
68. Kobayashi, T.; Matsuno, K.; Murai, M.; Mita, S. Sigma 1 receptor subtype is involved in the facilitation of cortical dopaminergic transmission in the rat brain. Neurochem. Res. 1997, 22, 1105-1109.

69. Minabe, Y.; Matsuno, K.; Ashby, C.R., Jr. Acute and chronic administration of the selective sigma1 receptor agonist SA4503 significantly alters the activity of midbrain dopamine neurons in rats: An in vivo electrophysiological study. Synapse 1999, 33, 129-140.

70. Hiranita, T.; Soto, P.L.; Tanda, G.; Katz, J.L. Reinforcing effects of sigma-receptor agonists in rats trained to self-administer cocaine. J. Pharmacol. Exp. Ther. 2010, 332, 515-524.

71. Pontieri, F.E.; Tanda, G.; di Chiara, G. Intravenous cocaine, morphine, and amphetamine preferentially increase extracellular dopamine in the "shell" as compared with the "core" of the rat nucleus accumbens. Proc. Natl. Acad. Sci. USA 1995, 92, 12304-12308.

72. Pontieri, F.E.; Tanda, G.; Orzi, F.; di Chiara, G. Effects of nicotine on the nucleus accumbens and similarity to those of addictive drugs. Nature 1996, 382, 255-257.

73. Tanda, G.; Pontieri, F.E.; di Chiara, G. Cannabinoid and heroin activation of mesolimbic dopamine transmission by a common mul opioid receptor mechanism. Science 1997, 276, 2048-2050.

74. Kalivas, P.W. The glutamate homeostasis hypothesis of addiction. Nat. Rev. Neurosci. 2009, 10, 561-572.

75. Bowers, M.S.; Chen, B.T.; Bonci, A. AMPA receptor synaptic plasticity induced by psychostimulants: The past, present, and therapeutic future. Neuron 2010, 67, 11-24.

76. Reissner, K.J.; Kalivas, P.W. Using glutamate homeostasis as a target for treating addictive disorders. Behav. Pharmacol. 2010, 21, 514-522.

77. Meyer, D.A.; Carta, M.; Partridge, L.D.; Covey, D.F.; Valenzuela, C.F. Neurosteroids enhance spontaneous glutamate release in hippocampal neurons. Possible role of metabotropic sigma1-like receptors. J. Biol. Chem. 2002, 277, 28725-28732.

78. Dong, L.Y.; Cheng, Z.X.; Fu, Y.M.; Wang, Z.M.; Zhu, Y.H.; Sun, J.L.; Dong, Y.; Zheng, P. Neurosteroid dehydroepiandrosterone sulfate enhances spontaneous glutamate release in rat prelimbic cortex through activation of dopamine D1 and sigma-1 receptor. Neuropharmacology 2007, 52, 966-974.

79. Schiess, A.R.; Partridge, L.D. Pregnenolone sulfate acts through a G-protein-coupled sigma1-like receptor to enhance short term facilitation in adult hippocampal neurons. Eur. J. Pharmacol. 2005, 518, 22-29.

80. Lhullier, F.L.; Nicolaidis, R.; Riera, N.G.; Cipriani, F.; Junqueira, D.; Dahm, K.C.; Brusque, A.M.; Souza, D.O. Dehydroepiandrosterone increases synaptosomal glutamate release and improves the performance in inhibitory avoidance task. Pharmacol. Biochem. Behav. 2004, 77, 601-606.

81. Chen, L.; Dai, X.N.; Sokabe, M. Chronic administration of dehydroepiandrosterone sulfate (DHEAS) primes for facilitated induction of long-term potentiation via sigma 1 (sigma1) receptor: Optical imaging study in rat hippocampal slices. Neuropharmacology 2006, 50, 380-392.

82. Li, Z.; Zhou, R.; Cui, S.; Xie, G.; Cai, W.; Sokabe, M.; Chen, L. Dehydroepiandrosterone sulfate prevents ischemia-induced impairment of long-term potentiation in rat hippocampal CA1 by 
up-regulating tyrosine phosphorylation of NMDA receptor. Neuropharmacology 2006, 51, 958-966.

83. Chen, B.T.; Bowers, M.S.; Martin, M.; Hopf, F.W.; Guillory, A.M.; Carelli, R.M.; Chou, J.K.; Bonci, A. Cocaine but not natural reward self-administration nor passive cocaine infusion produces persistent LTP in the VTA. Neuron 2008, 59, 288-297.

84. Russo, S.J.; Mazei-Robison, M.S.; Ables, J.L.; Nestler, E.J. Neurotrophic factors and structural plasticity in addiction. Neuropharmacology 2009, 56(Suppl), 73-82.

85. Ghitza, U.E.; Zhai, H.; Wu, P.; Airavaara, M.; Shaham, Y.; Lu, L. Role of BDNF and GDNF in drug reward and relapse: A review. Neurosci. Biobehav. Rev. 2010, 35, 157-171.

86. McGinty, J.F.; Whitfield, T.W., Jr.; Berglind, W.J. Brain-derived neurotrophic factor and cocaine addiction. Brain Res. 2010, 1314, 183-193.

87. Yagasaki, Y.; Numakawa, T.; Kumamaru, E.; Hayashi, T.; Su, T.P.; Kunugi, H. Chronic antidepressants potentiate via sigma-1 receptors the brain-derived neurotrophic factor-induced signaling for glutamate release. J. Biol. Chem. 2006, 281, 12941-12949.

88. Maurice, T.; Phan, V.L.; Privat, A. The anti-amnesic effects of sigma1 ([sigma]1) receptor agonists confirmed by in vivo antisense strategy in the mouse. Brain Res. 2001, 898, 113-121.

89. Sofuoglu, M. Cognitive enhancement as a pharmacotherapy target for stimulant addiction. Addiction 2010, 105, 38-48.

90. Junien, J.L.; Roman, F.J.; Brunelle, G.; Pascaud, X. JO1784, a novel sigma ligand, potentiates $[3 \mathrm{H}]$ acetylcholine release from rat hippocampal slices. Eur. J. Pharmacol. 1991, 200, 343-345.

91. Matsuno, K.; Matsunaga, K.; Senda, T.; Mita, S. Increase in extracellular acetylcholine level by sigma ligands in rat frontal cortex. J. Pharmacol. Exp. Ther. 1993, 265, 851-859.

92. Matsuno, K.; Senda, T.; Kobayashi, T.; Mita, S. Involvement of sigma 1 receptor in (+)-N-allylnormetazocine-stimulated hippocampal cholinergic functions in rats. Brain Res. 1995, 690, 200-206.

93. Kobayashi, T.; Matsuno, K.; Mita, S. Regional differences of the effect of sigma receptor ligands on the acetylcholine release in the rat brain. J. Neural. Transm. 1996, 103, 661-669.

94. Kobayashi, T.; Matsuno, K.; Nakata, K.; Mita, S. Enhancement of acetylcholine release by SA4503, a novel sigma 1 receptor agonist, in the rat brain. J. Pharmacol. Exp. Ther. 1996, 279, 106-113.

95. Matsuno, K.; Senda, T.; Kobayashi, T.; Okamoto, K.; Nakata, K.; Mita, S. SA4503, a novel cognitive enhancer, with sigmal receptor agonistic properties. Behav. Brain Res. 1997, 83, 221-224.

96. Maurice, T.; Phan, V.L.; Urani, A.; Guillemain, I. Differential involvement of the sigma(1) (sigma(1)) receptor in the anti-amnesic effect of neuroactive steroids, as demonstrated using an in vivo antisense strategy in the mouse. Br. J. Pharmacol. 2001, 134, 1731-1741.

97. Zheng, P. Neuroactive steroid regulation of neurotransmitter release in the CNS: Action, mechanism and possible significance. Prog. Neurobiol. 2009, 89, 134-152.

98. Romieu, P.; Martin-Fardon, R.; Maurice, T. Involvement of the sigmal receptor in the cocaine-induced conditioned place preference. Neuroreport 2000, 11, 2885-2888. 
99. Romieu, P.; Phan, V.L.; Martin-Fardon, R.; Maurice, T. Involvement of the sigma(1) receptor in cocaine-induced conditioned place preference: Possible dependence on dopamine uptake blockade. Neuropsychopharmacology 2002, 26, 444-455.

100. Martin-Fardon, R.; Maurice, T.; Aujla, H.; Bowen, W.D.; Weiss, F. Differential effects of sigmal receptor blockade on self-administration and conditioned reinstatement motivated by cocaine vs natural reward. Neuropsychopharmacology 2007, 32, 1967-1973.

101. Tanda, G.; Pontieri, F.E.; Frau, R.; di Chiara, G. Contribution of blockade of the noradrenaline carrier to the increase of extracellular dopamine in the rat prefrontal cortex by amphetamine and cocaine. Eur. J. Neurosci. 1997, 9, 2077-2085.

102. Snoddy, A.M.; Tessel, R.E. Prazosin: Effect on psychomotor-stimulant cues and locomotor activity in mice. Eur. J. Pharmacol. 1985, 116, 221-228.

103. Monnet, F.P.; Blier, P.; Debonnel, G.; de Montigny, C. Modulation by sigma ligands of $\mathrm{N}$-methyl-D-aspartate-induced $[3 \mathrm{H}]$ noradrenaline release in the rat hippocampus: G-protein dependency. Naunyn Schmiedebergs Arch. Pharmacol. 1992, 346, 32-39.

104. Gonzalez-Alvear, G.M.; Werling, L.L. Sigma1 Receptors in rat striatum regulate NMDA-stimulated [3H]dopamine release via a presynaptic mechanism. Eur. J. Pharmacol. 1995, 294, 713-719.

105. Weatherspoon, J.K.; Gonzalez-Alvear, G.M.; Werling, L.L. Regulation of [3H]norepinephrine release from guinea pig hippocampus by sigma2 receptors. Eur. J. Pharmacol. 1997, 326, 133-138.

106. Monnet, F.P.; Mahe, V.; Robel, P.; Baulieu, E.E. Neurosteroids, via sigma receptors, modulate the $[3 \mathrm{H}]$ norepinephrine release evoked by N-methyl-D-aspartate in the rat hippocampus. Proc. Natl. Acad. Sci. USA 1995, 92, 3774-3778.

107. Bermack, J.E.; Debonnel, G. Distinct modulatory roles of sigma receptor subtypes on glutamatergic responses in the dorsal hippocampus. Synapse 2005, 55, 37-44.

108. Ricaurte, G.A.; DeLanney, L.E.; Irwin, I.; Witkin, J.M.; Katz, J.L.; Langston, J.W. Evaluation of the neurotoxic potential of N,N-dimethylamphetamine: An illicit analog of methamphetamine. Brain Res. 1989, 490, 301-306.

109. Dong, L.; Zhu, Y.; Dong, Y.; Yang, J.; Zhao, Y.; Qi, Y.; Wu, P.; Zhu, Y.; Zheng, P. Neuroactive steroid dehydroepiandrosterone sulfate inhibits 5-hydroxytryptamine (5-HT)-evoked glutamate release via activation of sigma-1 receptors and then inhibition of 5-HT3 receptors in rat prelimbic cortex. J. Pharmacol. Exp. Ther. 2009, 330, 494-501.

110. Takahashi, S.; Horikomi, K.; Kato, T. MS-377, a novel selective sigma(1) receptor ligand, reverses phencyclidine-induced release of dopamine and serotonin in rat brain. Eur. J. Pharmacol. 2001, 427, 211-219.

111. Bermack, J.E.; Debonnel, G. Modulation of serotonergic neurotransmission by short- and long-term treatments with sigma ligands. Br. J. Pharmacol .2001, 134, 691-699.

112. Seminerio, M.J.; Kaushal, N.; Shaikh, J.; Huber, J.D.; Coop, A.; Matsumoto, R.R. Sigma (sigma) Receptor Ligand, AC927 (N-Phenethylpiperidine Oxalate), Attenuates MethamphetamineInduced Hyperthermia and Serotonin Damage in Mice. Pharmacol. Biochem. Behav. 2011, 98, 12-20. 
113. Mtchedlishvili, Z.; Kapur, J. A presynaptic action of the neurosteroid pregnenolone sulfate on GABAergic synaptic transmission. Mol. Pharmacol. 2003, 64, 857-864.

114. Maurice, T.; Gregoire, C.; Espallergues, J. Neuro(active)steroids actions at the neuromodulatory sigmal ([sigma]1) receptor: Biochemical and physiological evidences, consequences in neuroprotection. Pharmacol. Biochem. Behav. 2006, 84, 581-597.

115. Sharkey, J.; Glen, K.A.; Wolfe, S.; Kuhar, M.J. Cocaine binding at sigma receptors. Eur. J. Pharmacol. 1988, 149, 171-174.

116. Ritz, M.C.; George, F.R. Cocaine-induced seizures and lethality appear to be associated with distinct central nervous system binding sites. J. Pharmacol. Exp. Ther. 1993, 264, 1333-1343.

117. McCracken, K.A.; Bowen, W.D.; de Costa, B.R.; Matsumoto, R.R. Two novel sigma receptor ligands, BD1047 and LR172, attenuate cocaine-induced toxicity and locomotor activity. Eur. J. Pharmacol. 1999, 370, 225-232.

118. Matsumoto, R.R.; McCracken, K.A.; Friedman, M.J.; Pouw, B.; de Costa, B.R.; Bowen, W.D. Conformationally restricted analogs of BD1008 and an antisense oligodeoxynucleotide targeting sigmal receptors produce anti-cocaine effects in mice. Eur. J. Pharmacol. 2001, 419, 163-174.

119. Menkel, M.; Terry, P.; Pontecorvo, M.; Katz, J.L.; Witkin, J.M. Selective sigma ligands block stimulant effects of cocaine. Eur. J. Pharmacol. 1991, 201, 251-252.

120. Chausmer, A.L.; Katz, J.L. The role of D2-like dopamine receptors in the locomotor stimulant effects of cocaine in mice. Psychopharmacology (Berl) 2001, 155, 69-77.

121. Okuyama, S.; Imagawa, Y.; Ogawa, S.; Araki, H.; Ajima, A.; Tanaka, M.; Muramatsu, M.; Nakazato, A.; Yamaguchi, K.; Yoshida, M.; et al. NE-100, a novel sigma receptor ligand: In vivo tests. Life Sci. 1993, 53, PL285-PL290.

122. Matsumoto, R.R. Targeting sigma receptors: Novel medication development for drug abuse and addiction. Expert Rev. Clin. Pharmacol. 2009, 2, 351-358.

123. Ujike, H.; Tsuchida, K.; Akiyama, K.; Otsuki, S. Supersensitivity of sigma receptors after repeated administration of cocaine. Life Sci. 1992, 51, PL31-PL36.

124. Witkin, J.M.; Terry, P.; Menkel, M.; Hickey, P.; Pontecorvo, M.; Ferkany, J.; Katz, J.L. Effects of the selective sigma receptor ligand, 6-[6-(4-hydroxypiperidinyl)hexyloxy]-3-methylflavone (NPC 16377), on behavioral and toxic effects of cocaine. J. Pharmacol. Exp. Ther. 1993, 266, 473-482.

125. Takahashi, S.; Miwa, T.; Horikomi, K. Involvement of sigma 1 receptors in methamphetamineinduced behavioral sensitization in rats. Neurosci. Lett. 2000, 289, 21-24.

126. Okuyama, S.; Imagawa, Y.; Tomisawa, K. Behavioral evidence for modulation by sigma ligands of (+)MK-801-induced hyperlocomotion in monoamine-depleted mice. Neuropharmacology 1996, 35, 467-474.

127. Xu, X.; Domino, E.F. Cross-sensitization between phencyclidine and $(-)$ but not $(+)$ pentazocine. Pharmacol. Biochem. Behav. 1997, 56, 205-210.

128. Maurice, T.; Casalino, M.; Lacroix, M.; Romieu, P. Involvement of the sigma 1 receptor in the motivational effects of ethanol in mice. Pharmacol. Biochem. Behav. 2003, 74, 869-876.

129. Skuza, G.; Rogoz, Z. Antidepressant-like effect of PRE-084, a selective sigmal receptor agonist, in Albino Swiss and C57BL/6J mice. Pharmacol. Rep. 2009, 61, 1179-1183. 
130. Maj, J.; Rogoz, Z.; Skuza, G.; Mazela, H. Neuropharmacological profile of EMD 57445, a sigma receptor ligand with potential antipsychotic activity. Eur. J. Pharmacol. 1996, 315, 235-243.

131. Skuza, G. Effect of sigma ligands on the cocaine-induced convulsions in mice. Pol. J. Pharmacol. 1999, 51, 477-483.

132. Lever, J.R.; Gustafson, J.L.; Xu, R.; Allmon, R.L.; Lever, S.Z. Sigma1 and sigma2 receptor binding affinity and selectivity of SA4503 and fluoroethyl SA4503. Synapse 2006, 59, 350-358.

133. Matsuno, K.; Nakazawa, M.; Okamoto, K.; Kawashima, Y.; Mita, S. Binding properties of SA4503, a novel and selective sigma 1 receptor agonist. Eur. J. Pharmacol. 1996, 306, 271-279.

134. Rodvelt, K.R.; Lever, S.Z.; Lever, J.R.; Blount, L.R.; Fan, K.H.; Miller, D.K. SA 4503 attenuates cocaine-induced hyperactivity and enhances methamphetamine substitution for a cocaine discriminative stimulus. Pharmacol. Biochem. Behav. 2011, 97, 676-682.

135. Rodvelt, K.R.; Oelrichs, C.E.; Blount, L.R.; Fan, K.H.; Lever, S.Z.; Lever, J.R.; Miller, D.K. The sigma receptor agonist SA4503 both attenuates and enhances the effects of methamphetamine. Drug Alcohol Depend. 2011, 116, 203-210.

136. Holtzman, S.G. Discriminative Stimulu Effects of Drugs: Relationship to Potential for Abuse. In Testing and Evaluation of Drugs of Abuse. In Modern methods in pharmacology; Adler, M.W., Cowan, A., Eds.; Wiley-Liss: New York, NY, USA, 1990; Volume 6, pp. 193-210.

137. Witkin, J.M.; Nichols, D.E.; Terry, P.; Katz, J.L. Behavioral effects of selective dopaminergic compounds in rats discriminating cocaine injections. J. Pharmacol. Exp. Ther. 1991, 257, 706-713.

138. Holtzman, S.G. Discriminative stimulus effects of dextromethorphan in the rat. Psychopharmacology (Berl) 1994, 116, 249-254.

139. Gavend, M.; Mallaret, M.; Dematteis, M.; Baragatti, G. Discriminative stimulus properties of dextromethorphan in rats. Biomed. Pharmacother. 1995, 49, 456-464.

140. Steinfels, G.F.; Tam, S.W.; Cook, L. Discriminative stimulus properties of $(+)-\mathrm{N}$-allylnormetazocine in the rat: Correlations with $(+)-\mathrm{N}$-allylnormetazocine and phencyclidine receptor binding. Psychopharmacology (Berl) 1987, 91, 5-9.

141. Balster, R.L. Substitution and antagonism in rats trained to discriminate (+)-N-allylnormetazocine from saline. J. Pharmacol. Exp. Ther. 1989, 249, 749-756.

142. Singh, L.; Wong, E.H.; Kesingland, A.C.; Tricklebank, M.D. Evidence against an involvement of the haloperidol-sensitive sigma recognition site in the discriminative stimulus properties of (+)-N-allylnormetazocine ((+)-SKF 10,047). Br. J. Pharmacol. 1990, 99, 145-151.

143. Holtzman, S.G. Opioid- and phencyclidine-like discriminative effects of ditolylguanidine, a selective sigma ligand. J. Pharmacol. Exp. Ther. 1989, 248, 1054-1062.

144. Steinfels, G.F.; Alberici, G.P.; Tam, S.W.; Cook, L. Biochemical, behavioral, and electrophysiologic actions of the selective sigma receptor ligand (+)-pentazocine. Neuropsychopharmacology 1988, 1, 321-327.

145. Ukai, M.; Mori, E.; Kameyama, T. Modulatory effects of morphine, U-50488H and 1,3-di-(2-tolyl)guanidine on cocaine-like discriminative stimulus in the rat using two-choice discrete-trial avoidance paradigm. Methods Find Exp. Clin. Pharmacol. 1997, 19, 541-546.

146. Cohen, C.; Sanger, D.J. Effects of sigma ligands on the cocaine discriminative stimulus in rats. NIDA Res. Monogr. 1994, 153, 380. 
147. Hiranita, T.; Soto, P.; Tanda, G.; Katz, J. Lack of cocaine-like discriminative-stimulus effects of $\sigma$ receptor agonists in rats. Behav. Pharmacol. 2011, in press.

148. Colpaert, F.C.; Niemegeers, C.J.; Janssen, P.A. Discriminative stimulus properties of cocaine: Neuropharmacological characteristics as derived from stimulus generalization experiments. Pharmacol. Biochem. Behav. 1979, 10, 535-546.

149. Li, S.M.; Campbell, B.L.; Katz, J.L. Interactions of cocaine with dopamine uptake inhibitors or dopamine releasers in rats discriminating cocaine. J. Pharmacol. Exp. Ther. 2006, 317, 1088-1096.

150. Hundt, W.; Danysz, W.; Holter, S.M.; Spanagel, R. Ethanol and N-methyl-D-aspartate receptor complex interactions: A detailed drug discrimination study in the rat. Psychopharmacology (Berl) 1998, 135, 44-51.

151. Holtzman, S.G. Discriminative stimulus effects of buprenorphine in the rat. Psychopharmacology (Berl) 1997, 130, 292-299.

152. Tzschentke, T.M. Measuring reward with the conditioned place preference paradigm: A comprehensive review of drug effects, recent progress and new issues. Prog. Neurobiol. 1998, 56, 613-672.

153. Horan, B.; Gardner, E.L.; Dewey, S.L.; Brodie, J.D.; Ashby, C.R., Jr. The selective sigma(1) receptor agonist, 1-(3,4-dimethoxyphenethyl)-4-(phenylpropyl)piperazine (SA4503), blocks the acquisition of the conditioned place preference response to (-)-nicotine in rats. Eur. J. Pharmacol. 2001, 426, R1-R2.

154. Iwamoto, E.T. Place-conditioning properties of mu, kappa, and sigma opioid agonists. Alcohol Drug Res. 1985, 6, 327-339.

155. Romieu, P.; Martin-Fardon, R.; Bowen, W.D.; Maurice, T. Sigma 1 receptor-related neuroactive steroids modulate cocaine-induced reward. J. Neurosci. 2003, 23, 3572-3576.

156. Slifer, B.L.; Balster, R.L. Reinforcing properties of stereoisomers of the putative sigma agonists $\mathrm{N}$-allylnormetazocine and cyclazocine in rhesus monkeys. J. Pharmacol. Exp. Ther. 1983, 225, 522-528.

157. Katz, J.L.; Higgins, S.T. The validity of the reinstatement model of craving and relapse to drug use. Psychopharmacology (Berl) 2003, 168, 21-30.

158. Hiranita, T.; Soto, P.L.; Newman, A.H.; Katz, J.L. Assessment of reinforcing effects of benztropine analogs and their effects on cocaine self-administration in rats: Comparisons with monoamine uptake inhibitors. J. Pharmacol. Exp. Ther. 2009, 329, 677-686.

159. Liu, Y.; Chen, G.D.; Lerner, M.R.; Brackett, D.J.; Matsumoto, R.R. Cocaine up-regulates Fra-2 and sigma-1 receptor gene and protein expression in brain regions involved in addiction and reward. J. Pharmacol. Exp. Ther. 2005, 314, 770-779.

160. Liu, Y.; Matsumoto, R.R. Alterations in fos-related antigen 2 and sigmal receptor gene and protein expression are associated with the development of cocaine-induced behavioral sensitization: Time course and regional distribution studies. J. Pharmacol. Exp. Ther. 2008, 327, 187-195.

161. Stefanski, R.; Justinova, Z.; Hayashi, T.; Takebayashi, M.; Goldberg, S.R.; Su, T.P. Sigma1 receptor upregulation after chronic methamphetamine self-administration in rats: A study with yoked controls. Psychopharmacology (Berl) 2004, 175, 68-75. 
162. Stefanski, R.; Ladenheim, B.; Lee, S.H.; Cadet, J.L.; Goldberg, S.R. Neuroadaptations in the dopaminergic system after active self-administration but not after passive administration of methamphetamine. Eur. J. Pharmacol. 1999, 371, 123-135.

163. Hayashi, T.; Justinova, Z.; Hayashi, E.; Cormaci, G.; Mori, T.; Tsai, S.Y.; Barnes, C.; Goldberg, S.R.; Su, T.P. Regulation of sigma-1 receptors and endoplasmic reticulum chaperones in the brain of methamphetamine self-administering rats. J. Pharmacol. Exp. Ther. 2010, 332, 1054-1063.

164. Ben-Ami, O.; Kinor, N.; Perelman, A.; Yadid, G. Dopamine-1 receptor agonist, but not cocaine, modulates sigma(1) gene expression in SVG cells. J. Mol. Neurosci. 2006, 29, 169-176.

165. Zhang, D.; Zhang, L.; Tang, Y.; Zhang, Q.; Lou, D.; Sharp, F.R.; Zhang, J.; Xu, M. Repeated cocaine administration induces gene expression changes through the dopamine D1 receptors. Neuropsychopharmacology 2005, 30, 1443-1454.

(C) 2011 by the authors; licensee MDPI, Basel, Switzerland. This article is an open access article distributed under the terms and conditions of the Creative Commons Attribution license (http://creativecommons.org/licenses/by/3.0/). 